
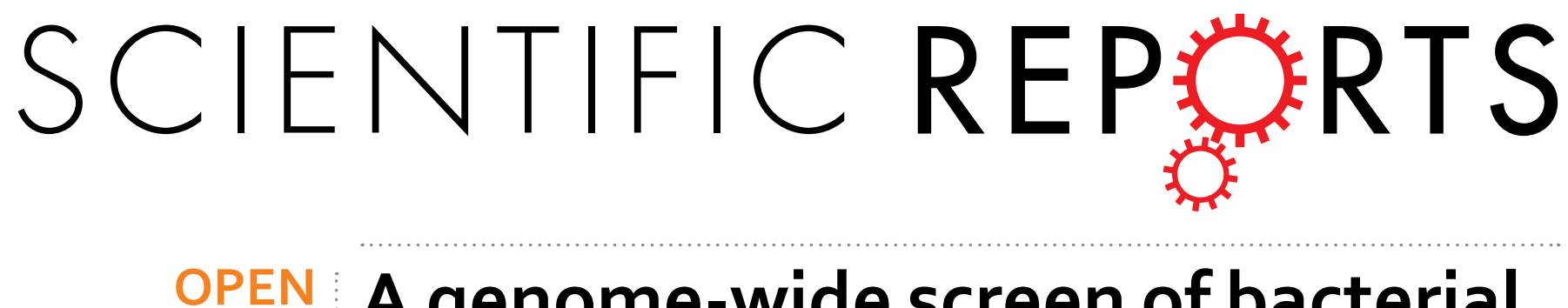

\title{
A genome-wide screen of bacterial mutants that enhance dauer formation in C. elegans
}

Received: 20 May 2016

Accepted: 10 November 2016

Published: 13 December 2016
Amit Khanna ${ }^{1,{ }^{*}}$, Jitendra Kumar ${ }^{1,{ }^{*}}$, Misha A. Vargas ${ }^{1,{ }^{*}}$, LaKisha Barrett ${ }^{1}$, Subhash Katewa ${ }^{1}$, Patrick Li ${ }^{1}$, Tom McCloskey ${ }^{1}$, Amit Sharma ${ }^{1}$, Nicole Naudé ${ }^{1}$, Christopher Nelson ${ }^{1}$, Rachel Brem ${ }^{1}$, David W. Killilea ${ }^{2}$, Sean D. Mooney ${ }^{3}$, Matthew Gill ${ }^{4}$ \& Pankaj Kapahi ${ }^{1}$

Molecular pathways involved in dauer formation, an alternate larval stage that allows Caenorhabditis elegans to survive adverse environmental conditions during development, also modulate longevity and metabolism. The decision to proceed with reproductive development or undergo diapause depends on food abundance, population density, and temperature. In recent years, the chemical identities of pheromone signals that modulate dauer entry have been characterized. However, signals derived from bacteria, the major source of nutrients for $C$. elegans, remain poorly characterized. To systematically identify bacterial components that influence dauer formation and aging in C. elegans, we utilized the individual gene deletion mutants in $E$. coli (K12). We identified 56 diverse $E$. coli deletion mutants that enhance dauer formation in an insulin-like receptor mutant (daf-2) background. We describe the mechanism of action of a bacterial mutant cyaA, that is defective in the production of cyclic AMP, which extends lifespan and enhances dauer formation through the modulation of TGF- $\beta$ (daf- 7 ) signaling in C. elegans. Our results demonstrate the importance of bacterial components in influencing developmental decisions and lifespan in C. elegans. Furthermore, we demonstrate that $C$. elegans is a useful model to study bacterial-host interactions.

The soil-dwelling nematode, C. elegans, assesses environmental cues including food availability, temperature, and population density ${ }^{1,2}$, to determine the choice between reproduction and survival ${ }^{2}$. Under favorable conditions, C. elegans attains reproductive maturity, but under adverse environments, worms enter dauer diapause, a long-lived stress resistant stage ${ }^{2}$. There are at least two types of chemical signals that dictate this developmental decision; a) dauer pheromones, a complex mixture of small molecules called ascarosides whose levels depend on worm population density ${ }^{3-6}$, and b) signals derived from bacteria that promote development ${ }^{3}$.

To detect microbial metabolites in the environment C. elegans has evolved multiple mechanisms, which allow discrimination between bacterial species that are appropriate food sources and those that are pathogenic or inferior in quality ${ }^{7,8}$. The chemosensory system senses bacterial metabolites in the local environment and modulates the organismal response to signaling through conserved molecular pathways ${ }^{1,2,9}$. These include the transforming growth factor beta (TGF- $\beta$ ), guanylyl cyclase, and insulin-like signaling (ILS) pathways, which ultimately converge to modulate the activity of key factors such as forkhead transcription factor (DAF-16/FOXO) ${ }^{2-4,10-12}$. The activity of DAF-16 is pivotal in determining the organism's response, to either engage in reproductive growth or to enter dauer arrest state ${ }^{2,13}$. Although the genetic pathways that modulate dauer formation are relatively well understood, the identities of the signals that influence dauer formation remain poorly defined. C. elegans is known to respond to signals emanating from bacteria to detect food sources ${ }^{8}$, and a recent report identified bacterial fatty acids as a signal that modulates recovery from the dauer stage ${ }^{14}$. It is likely that the worm integrates a multitude of bacterial signals through the chemosensory system to make appropriate developmental decisions which remain undiscovered.

${ }^{1}$ Buck Institute for Research on Aging, 8001 Redwood Blvd, Novato, USA. ${ }^{2}$ Nutrition \& Metabolism Center, Children's Hospital Oakland Research Institute, 5700 Martin Luther King Jr. Way, Oakland, CA, USA. ${ }^{3}$ Department of Biomedical Informatics and Medical Education, University of Washington, Seattle, Washington 98195, USA. ${ }^{4}$ Department of Metabolism \& Aging, The Scripps Research Institute- Scripps Florida, Jupiter, Florida, 33458, USA. *These authors contributed equally to this work. Correspondence and requests for materials should be addressed to P.K. (email: Pkapahi@buckInstitute.org) 


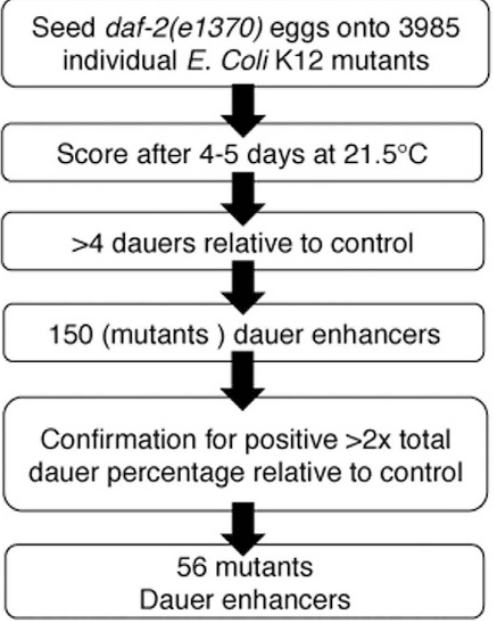

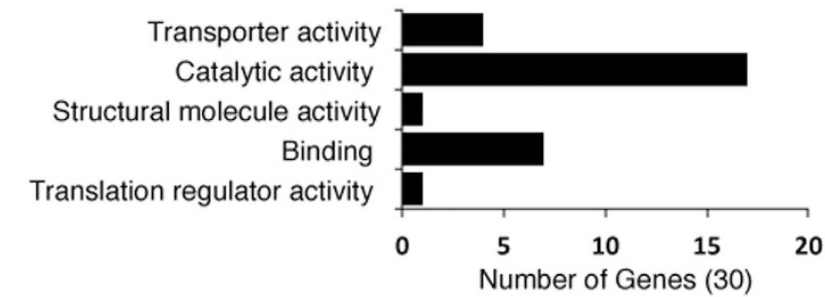

PANTHER Cellular Component Analysis (Dauer enhancers)

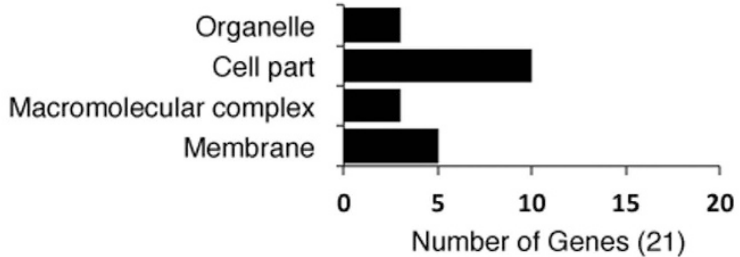

Figure 1. Schematic of the E. coli knockout screen for dauer formation in C. elegans and functional classifications of identified bacterial genes. (a) Schematic of the workflow of $E$. coli knockout screen for dauer enhancement in C. elegans. The screen resulted in 56 mutant bacterial strains enhancing dauer formation in the worm. The knockout candidates and associated statistical information are available on Table 1. (b) Functional classification of candidate genes (dauer enhancers) from the screen. The molecular function analysis of the candidate genes was done using PANTHER pathway database. (c) The cellular component analysis of these genes was done using PANTHER pathway database. For details pertaining to biological function analysis and enrichment analysis see Fig. S1.

Dauer formation provides an easy to assess, binary readout of the type of food signals emanating from bacteria. Here we demonstrate how multiple individual gene knockouts in E. coli can influence development and survival in C. elegans. Through a systematic screen of $\sim 4000$ single gene knockout $E$. coli strains, we identified 56 E. coli mutants that enhanced dauer formation in a C. elegans insulin-like receptor mutant, daf-2, some of which also extended adult lifespan in control worms. One of the largest lifespan extensions was observed by feeding the bacterial mutant, cyaA (adenylate cyclase). We identify that $c y a A$ influences TGF- $\beta$ signaling to modulate dauer formation and lifespan. Our results demonstrate that the combination of bacterial and worm genetics can be a powerful tool to study bacterial-host interactions that influence nutrient signaling pathways and organismal physiology that may be relevant for host-microbiome interactions in other species.

\section{Results}

Bacterial mutants enhance dauer formation in daf-2 (e1370) mutants. To systematically study bacterial products that could act as food signals in C. elegans, we fed worms with bacterial strains from the E. coli Keio knockout library. The library consists of 3985 single-gene in-frame knockout mutants, with individual genes precisely excised and replaced with a Kanamycin resistance cassette in a K-12 BW25113 background ${ }^{15}$. To study the impact of bacteria on organismal physiology we screened for bacterial mutants that enhance dauer formation in a daf-2(e1370) mutant background. This worm strain carries a hypomorphic mutation in the insulin receptor ortholog gene that results in reduced flux through the ILS pathway and triggers constitutive dauer formation at high temperatures but undergoes normal development at low temperatures ${ }^{12,16-19}$. We carried out the screen at a semi-permissive temperature $\left(21.5^{\circ} \mathrm{C}\right)$, which allowed most worms on the control K-12 E. coli strain to develop to adulthood, with a small percentage entering the dauer stage. This assay created a sensitive readout to detect bacterial food signals in the diet, which influence organismal physiology detected by an increase in dauer formation in the worm.

In the primary screen, approximately 60 eggs were seeded onto plates with mutant $E$. coli strains and monitored for dauer formation after 4-5 days. The total number of dauers on the K-12 control strain was used as a reference and knockout strains that produced at least four more dauer animals than the control strain were marked as positive candidates and retested. This second, and more stringent, round of screening examined 150 knockout candidates in triplicate, and knockouts that at least doubled the total dauer percentage of worms developed on the K-12 control strain were scored as positive (Fig. 1a). Using this approach, we identified 56 mutant $E$. coli strains that robustly enhanced entry into the dauer stage (Table 1). PCR with gene-specific primers was performed to confirm gene deletion in the knockout mutants (Fig. S1A). As negative controls, ten knockout strains that were not identified in the primary screen were randomly chosen and thoroughly tested for dauer formation. These strains did not show any significant alteration in the rate of dauer formation when compared to controls (Fig. S1B).

To identify the biological pathways and cellular functions affected by the bacterial mutants that influenced dauer formation, the candidates were analyzed using PANTHER classification system ${ }^{20,21}$. Out of 56 genes, 9 genes are not characterized, and the remaining 47 genes were analyzed for molecular and biological functions 


\begin{tabular}{|c|c|c|c|c|c|c|}
\hline $\begin{array}{l}\text { Gene } \\
\text { Knockout }\end{array}$ & Brief Description & $\begin{array}{l}\text { Func. } \\
\text { Group }\end{array}$ & $\operatorname{Mean}(\%)^{\mathrm{a}}$ & $\pm \mathbf{S E}^{\mathrm{b}}$ & $\mathbf{n}^{\mathrm{c}}$ & $p$-Value ${ }^{\mathrm{d}}$ \\
\hline $\mathrm{K}-12$ & Control & 1 & 12.6 & 1.5 & 231 & l \\
\hline moaD & molybdopterin synthase, small subunit & MET & 81.9 & 3.2 & 117 & $<0.0001$ \\
\hline JW09292 & zapC: cell division factor, localises to the cytokinetics ring & OTR & 79.0 & 2.6 & 309 & $<0.0001$ \\
\hline fdoG & $\alpha$ subunit of formate dehydrogenase $\mathrm{O}$ & MET & 77.7 & 0.9 & 63 & $<0.0001$ \\
\hline JW1330 & abgT; predicted cryptic aminobenzoyl-glutamate transporter & MET & 72.1 & 3.5 & 222 & $<0.0001$ \\
\hline Lar & Rac prophae: restriction alleviation protein & OTR & 70.2 & 2.0 & 145 & $<0.0001$ \\
\hline panE & 2-dehydropantoate reductase, NADPH-specific & MET & 68.6 & 3.8 & 98 & $<0.0001$ \\
\hline $\mathrm{mdoH}$ & glucan biosynthesis: glycosyl transferase & CEB & 67.5 & 7.4 & 96.0 & 0.00 \\
\hline yjgB & $\begin{array}{l}\text { predicted alcohol dehydrogenase, } Z n \text {-dependent and } \\
\text { NAD(P)-binding }\end{array}$ & UNK & 67.5 & 3.3 & 180 & $<0.0001$ \\
\hline elaA & $\begin{array}{l}\text { predicted acyltransferase, Zn- dependent and NAD(P)- } \\
\text { binding }\end{array}$ & UNK & 66.7 & 3.2 & 207 & $<0.0001$ \\
\hline kdpB & potassium translocating ATPase, subunit B & ITM & 66.4 & 17.5 & 103 & 0.04 \\
\hline dcuC & anaerobic C4-dicarboxylate transport & MET & 65.2 & 1.6 & 186 & $<0.0001$ \\
\hline mutS & methyl-directed mismatch repair protein & DNA & 64.4 & 3.6 & 209 & $<0.0001$ \\
\hline htrG & predicted signal transduction protein (SH3 domain) & UNK & 64.3 & 5.4 & 194 & $<0.0001$ \\
\hline dhaH & $\begin{array}{l}\text { fused predicted dihydroxyacetone-specific PTS enzymes: HPr } \\
\text { component }\end{array}$ & MET & 63.4 & 11.4 & 63 & 0.01 \\
\hline $\operatorname{rimK}$ & ribosomal protein S6 modification protein & TRN & 62.8 & 3.3 & 72 & $<0.0001$ \\
\hline gloB & predicted hydroxyacylglutathione hydrolase & MET & 62.6 & 8.6 & 95.0 & 0.00 \\
\hline clpX & $\begin{array}{l}\text { ATPase and specificity subunit of ClpX-ClcP ATP-dependent } \\
\text { serine protease }\end{array}$ & TRN & 62.4 & 2.3 & 175 & $<0.0001$ \\
\hline tufa & protein chain elongation factor EF-Tu (duplicate of tuFB) & TRN & 60.7 & 3.0 & 69 & $<0.0001$ \\
\hline ybeA & 23S rRNA m $\psi 1915$ methyltranferase & OTR & 60.2 & 7.6 & 250 & 0.00 \\
\hline JW0632 & ybeB; predicted protein & UNK & 58.7 & 6.4 & 190 & 0.00 \\
\hline $\mathrm{rfaD}$ & ADP-L-glycero-D-mannoheptose-6-epimerase & CEB & 58.3 & 5.0 & 146 & $<0.0001$ \\
\hline yjiK & conserved protein & UNK & 56.4 & 5.4 & 151 & 0.00 \\
\hline fdoH & formate dehydrogenase-O, Fe-S subunit & MET & 56.0 & 10.7 & 65 & 0.02 \\
\hline yncA & $\begin{array}{l}\text { predicted acyltransferase with acyl-CoA N-acyltransferase } \\
\text { domain }\end{array}$ & CEB & 55.8 & 9.5 & 135 & 0.01 \\
\hline fepB & iron-enterbactin transporter subunit & ITM & 53.2 & 10.3 & 309 & 0.01 \\
\hline hsdS & specificity detereminant for hsdM and hsdR & DNA & 52.3 & 6.6 & 188 & 0.00 \\
\hline ygiQ & conserved protein & UNK & 51.0 & 9.2 & 63 & 0.01 \\
\hline Ung & iron-enterbactin transporter subunit & DNA & 50.6 & 11.6 & 70 & 0.03 \\
\hline hdfR & DNA-binding transcriptional regulator & TRX & 50.4 & 16.3 & 200 & 0.08 \\
\hline yjbD & conserved protein & UNK & 49.2 & 4.0 & 180 & 0.00 \\
\hline fepC & iron-enterbactin transporter subunit & ITM & 47.8 & 4.9 & 142 & 0.00 \\
\hline hypE & $\begin{array}{l}\text { carbomoyl phosphate phosphatase, hydrogenase } 3 \text { maturation } \\
\text { protein }\end{array}$ & TRN & 45.2 & 7.4 & 105 & 0.01 \\
\hline JW5726 & phnl, phnH; carbon-phosphorus lyase complex subunit & ITM & 43.5 & 4.2 & 112 & 0.00 \\
\hline ydhF & predicted oxidoreductase & UNK & 43.1 & 6.0 & 145 & 0.01 \\
\hline yqeH & conserved protein with bipartite regulator domain & TRX & 42.1 & 4.4 & 117 & 0.00 \\
\hline yjgN & conserved inner membrane protein & UNK & 41.4 & 4.8 & 97 & 0.00 \\
\hline JW1321.5 & Unknown & UNK & 40.0 & 5.7 & 236 & 0.01 \\
\hline cyaA & adenylate cyclase & OTR & 39.6 & 7.5 & 66.0 & 0.02 \\
\hline moaE & molybdopterin synthase, small subunit & MET & 38.3 & 7.7 & 82 & 0.03 \\
\hline sufA & Fe-S cluster assembly protein & MET & 37.6 & 5.1 & 229 & 0.01 \\
\hline sufE & sulphur acceptor protein & MET & 36.6 & 5.1 & 211 & 0.01 \\
\hline yggX & $\begin{array}{l}\text { protein that protects iron-sulfur proteins against oxidative } \\
\text { damage }\end{array}$ & TRN & 36.1 & 8.1 & 352 & 0.05 \\
\hline yheM & predicted intracellular sulfur oxidation protein & ITM & 36.0 & 2.8 & 208 & 0.00 \\
\hline yedR & predicted inner membrane protein & UNK & 33.5 & 8.1 & 294 & 0.07 \\
\hline fepG & iron-enterbactin transporter subunit & ITM & 32.3 & 6.8 & 195 & 0.03 \\
\hline yicM & purine ribonucleoside exporter & MET & 32.2 & 9.0 & 187 & 0.10 \\
\hline $\mathrm{dmsC}$ & dimethyl sulfoxide reductase, anaerobic, subunit $\mathrm{C}$ & MET & 32.1 & 1.8 & 111 & 0.00 \\
\hline yjgX & KpLE2 phage-like element; predicted protein (pseudogene) & UNK & 31.8 & 4.8 & 181 & 0.02 \\
\hline yrfD & predicted pilus assembly protein & MET & 31.6 & 4.9 & 195 & 0.02 \\
\hline srlA & glucitol/sorbitol -specific enzyme IIC component of PTS & MET & 30.6 & 4.0 & 323 & 0.01 \\
\hline \multicolumn{7}{|c|}{ Continued } \\
\hline
\end{tabular}




\begin{tabular}{|c|c|c|c|c|c|c|}
\hline $\begin{array}{l}\text { Gene } \\
\text { Knockout }\end{array}$ & Brief Description & $\begin{array}{l}\text { Func. } \\
\text { Group }\end{array}$ & $\operatorname{Mean}(\%)^{\mathrm{a}}$ & $\pm \mathbf{S E}^{\mathbf{b}}$ & $\mathbf{n}^{\mathrm{c}}$ & $p$-Value ${ }^{\mathrm{d}}$ \\
\hline pepA & aminopeptidase A, a cyteinylglycinase & MET & 29.8 & 2.6 & 216 & 0.00 \\
\hline yfaS & predicted protein (pseudogene) & UNK & 29.7 & 4.5 & 223 & $<0.0001$ \\
\hline Yjhc & KpLE2 phage-like element; predicted oxidoreducatse & UNK & 29.7 & 1.6 & 247.0 & $<0.001$ \\
\hline tolA & membrane anchored protein involved in colicin uptake & CEB & 29.2 & 3.8 & 186 & 0.02 \\
\hline ygjQ & predicted thioredoxin-like & UNK & 28.6 & 1.7 & 252 & 0.00 \\
\hline уqјH & predicted siderophore interacting protein & ITM & 28.3 & 1.0 & 367 & $<0.0001$ \\
\hline
\end{tabular}

Table 1. List of bacterial mutants that enhance dauer formation. E. coli knockouts were identified as portrayed in Fig. 1a and functional groups were delineated as described in text and Fig. 1b. Brief descriptions were adapted from EcoCyc. Functional codes were abbreviated as follows: MET, metabolism; ITM, inorganic ion transport and metabolism; TRN, translation, posttranslational modification, protein turnover, chaperones; CEB, cell envelope biogenesis, outer membrane; DNA, DNA replication, recombination and repair; TRX,

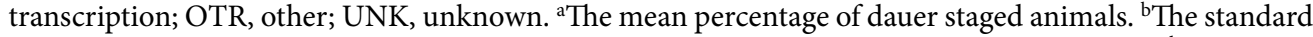
error of the mean in percent. ${ }^{c}$ The total number of individuals scored (includes all replicates). ${ }^{\mathrm{d}}$ The $p$-value for a student's two-tailed t-test comparing respective E. coli gene knockout strain to control strain.

(Fig. 1b and Fig. S1C). The following broad molecular functional categories were identified: translation regulator activity (GO:0045182) (4 genes). binding (GO:0005488) (7 genes), structural molecule activity (GO:0005198) (1 gene), catalytic activity (GO:0003824) (17 genes), transporter activity (GO:0005215) (4 genes) (Fig. 1b). Using the PANTHER classification system the cellular site of action of the product of these genes was identified:membrane (GO:0016020), macromolecular complex (GO:0032991), cell part (GO:0044464) and organelle (GO:0043226) (Fig. 1c). Furthermore, the candidate genes were analyzed and assigned functional groups utilizing Clusters of Orthologous Group (COG) terms ${ }^{22}$ and confirmed with MultiFun ${ }^{23}$ and Gene Ontology (GO) classifications ${ }^{24}$. Categorization of the genes revealed the enrichment in the following functional groups: metabolism $(\sim 39 \%)$; inorganic ion transport and metabolism $(\sim 17 \%)$; translation, post-translational modification, protein turnover $(\sim 12 \%)$, and chaperones; cell envelope biogenesis and outer membrane structures $(\sim 10 \%)$; DNA replication, recombination and repair $(\sim 7 \%)$; transcription $(\sim 5 \%)$; and rest other functions $(\sim 10 \%)$ (Table 1 and Fig. S1D). Furthermore, several of the genes from the screen fell within functional groups and transcriptional units, e.g. operons and regulons (Fig. S1E). Together these findings indicate that the bacterial genes with a broad range of cellular functions and processes can alter C. elegans physiology through changes in bacteria derived metabolites or nutrients.

Phenotypic analyses of bacterial mutants that enhance dauer formation for DAF-16 activation and lifespan extension. The phosphorylation cascade elicited by an activated ILS negatively regulates DAF16 by sequestering it in the cytoplasm. Conversely, reduced ILS signaling leads to diminished phosphorylation of DAF-16, thereby allowing it to enter the nucleus and modify gene expression ${ }^{25,26}$. Given the effects of the bacterial mutants on dauer formation in the daf-2 mutant, we examined whether they would also impact DAF-16 in adult animals. A majority ( $\sim 63 \%)$ of the bacterial mutants promoted DAF-16 nuclear localization in a worm strain expressing a DAF-16::GFP (daf-16(mgDf47)) fusion construct (Fig. 2 and Fig. S2A). Once DAF-16 enters the nucleus it can modulate the transcription of its targets, such as the stress-responsive superoxide dismutase, SOD$3^{27}$. Consistently, $\sim 64 \%$ of the bacterial mutants also increased SOD-3p::GFP expression in an N2 control background, while $\sim 80 \%$ of the bacterial knockouts increased sod-3 expression in the daf-2(e1370) background (Fig. 2 and Fig. S2A). No significant effects on sod-3 expression were noted in the 10 negative controls used previously, compared to animals fed control bacteria (data not shown). Lastly, of the 35 bacterial candidates that showed DAF-16 nuclear localization, 26 induced sod-3p::GFP in N2 background, while 32 induced GFP in the daf-2;sod$3 p:: G F P$ strain (Fig. 2). Taken together these data suggest that the majority of E. coli mutants from the screen stimulate DAF-16 translocation and/or subsequent regulation of its transcriptional targets in both the daf-2 mutant and control (N2) worms.

In addition to regulating dauer entry during development, DAF-16 exhibits transcriptional control over genes determining longevity in the adult worm ${ }^{27,28}$. Thus, we assessed the effect of each bacterial strain identified in the screen on the survival of N2, daf-2, and daf-16; daf-2 strains. Feeding several of the E. coli knockout strains resulted in increased lifespan in both the daf- 2 and control (N2) background. However, $\sim 61 \%$ of the bacterial mutants significantly extended the average lifespan of $d a f-2$ mutants compared to $\sim 38 \%$ in the control N2 strain. (Fig. 2, Table 2 and Fig. S2B). These observations were similar to the results obtained with the sod-3::gfp expression (Fig. 2), which can potentially be explained as the screen was carried out in a sensitized daf-2 mutant background. Although most of the knockout bacteria appear to modulate lifespan in a daf-16-dependent manner (Fig. 2 and Table 2), some bacterial mutants (e.g. tolA, and $y j b D$ ) extended lifespan in daf-16; daf-2 mutant worms, indicating that a genetically modified diet may also affect longevity by daf-16-independent mechanisms.

Several of the identified bacterial genes appear to have highly directed roles in micronutrient or metabolite production or transport (Table 1 and Fig. S1E). For example, $f e p B, C$, and $G$ have roles in the iron import system. dhaH has an enzymatic role in the production of dihydroxyacetone phosphate, while $s r l A, y j h c$, and $m d o H$ are involved in the production of sorbitol, $\mathrm{N}$-acetylneuraminic acid (sialic acid), and periplasmic glucans, respectively. One of the largest lifespan extension was observed with cyaA, which encodes adenylate cyclase that catalyzes the conversion of ATP to Adenosine $3^{\prime}, 5^{\prime}$-cyclic monophosphate (cAMP) and pyrophosphate ${ }^{15}$. In bacteria, intracellular cAMP signaling modulates the expression of catabolic proteins with biosynthetic and 

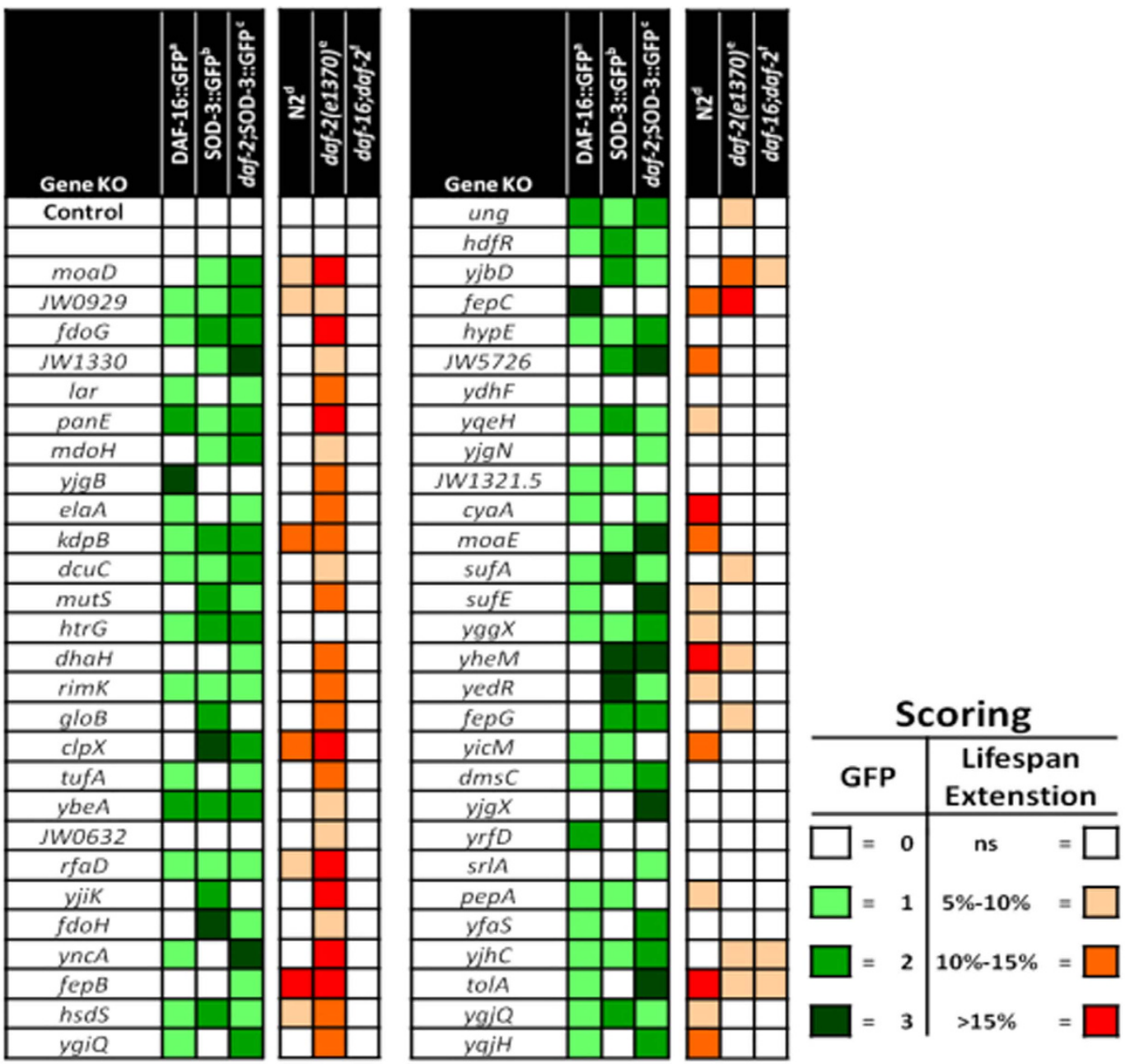

Figure 2. Analysis of DAF-16 activation and lifespan extension in bacterial knockouts that enhance C. elegans dauer formation. Heat map showing various phenotypes observed with bacterial mutants (left to right). (a) Semi-quantitative analysis of DAF-16 nuclear localization is shown following feeding on listed E. coli knockouts. Increased green shading correlates with increasing nuclear localization of DAF-16. (Fig. S2) (b) sod-3p::GFP expression is shown following feeding on listed E. coli knockouts. Increased green shading correlates with increasing sod-3p::GFP expression. (c) daf-2(e1370); sod-3p::GFP expression is shown following feeding on listed $E$. coli knockouts. Increased green shading correlates with increasing daf-2(e1370);sod-3p::GFP expression. In each visual marker $(\mathbf{a}-\mathbf{c})$ knockout strains are given a score relative to its $\mathrm{K}-12$ control, which was consistently set at a score of 0 (white shading). (d-f) Lifespan analysis of respective worm strains following feeding on bacterial knockout strains throughout life. Deeper red shading indicates increased average lifespan compared to K-12 control strain. Representative lifespan curves and lifespan data analysis are shown in Fig. S2 and Table 2 respectively.

ribosomal proteins according to cellular metabolic needs during exponential growth ${ }^{29}$. We further characterized cyaA mutant bacteria to determine the role of bacterial cAMP in modulating insulin signaling, dauer formation and lifespan in C. elegans.

CAMP modulates lifespan and dauer formation in C.elegans. We examined whether the effect of cyaA mutant bacteria on dauer formation was a consequence of reduced levels of cAMP. We confirmed that cyaA gene is disrupted (Fig. S1) and cAMP levels were indeed reduced in cyaA mutant bacteria (Fig. 3a). Next, we found that supplementation with $2 \mathrm{mM}$ exogenous cAMP could restore levels back to those observed in K12 bacteria (Fig. 3a). Also, we did not see any significant difference in the bacterial growth curves between cyaA mutant bacteria as compared K-12 bacteria under minimal media conditions (Fig. S3A). The uptake of cAMP has been shown to be variable in bacteria and exhibits saturation kinetics based on the culture conditions ${ }^{30}$. Also, worms fed on cyaA mutant bacteria did not display any apparent adverse effects on worm physiology, as we did not observe any significant change in physiological parameters such as body size, lawn leaving behavior or pharyngeal pumping in control animals (N2) fed on cyaA mutant bacteria (Fig. S3B-G). Furthermore, bacterial choice assays suggested that the N2 worms preferred K-12 control bacteria to cyaA and other mutant bacteria that enhance dauer formation (Fig. $\mathrm{S} 3 \mathrm{H}$ ). 


\begin{tabular}{|c|c|c|c|c|c|c|c|c|c|c|c|c|}
\hline \multirow{2}{*}{$\begin{array}{l}\text { Gene } \\
\text { Knockout }\end{array}$} & \multicolumn{4}{|c|}{$\mathrm{N} 2$} & \multicolumn{4}{|c|}{ daf-2(e1370) } & \multicolumn{4}{|c|}{ daf-16(mu86); daf-2(e1370) } \\
\hline & Mean $^{\mathrm{a}}$ & Change $^{\mathrm{b}}$ & $\mathbf{n}^{\mathrm{c}}$ & $p$-Value $^{\mathrm{d}}$ & Mean $^{\mathrm{a}}$ & change $^{b}$ & $\mathrm{n}^{\mathrm{c}}$ & $p$-Value ${ }^{\mathrm{d}}$ & Mean $^{\mathrm{a}}$ & Change $^{\mathrm{b}}$ & $\mathbf{n}^{\mathrm{c}}$ & $p$-Value ${ }^{\mathrm{d}}$ \\
\hline $\mathrm{K}-12$ & $13.9 \pm 0.4$ & 1 & 248 & - & $26.4 \pm 0.9$ & 1 & 278 & - & $12.7 \pm 0.3$ & 1 & 264 & \\
\hline moaD & 15.1 & $8.7 \%$ & 11 & 0.0076 & 31.3 & $18.5 \%$ & 106 & $<0.0001$ & 13.2 & I & 96 & \\
\hline JW09292 & 14.6 & $5.2 \%$ & 131 & $<0.0001$ & 28.6 & $8.2 \%$ & 116 & $<0.0001$ & 13.1 & 1 & 116 & \\
\hline fdoG & 12.9 & I & 93 & & 30.4 & $15.1 \%$ & 107 & $<0.0001$ & 13 & I & 91 & \\
\hline JW1330 & 14.5 & I & 124 & & 28.5 & $7.9 \%$ & 109 & 0.0315 & 12.6 & I & 73 & \\
\hline Lar & 13.5 & 1 & 99 & & 29.4 & $11.5 \%$ & 109 & $<0.0001$ & 12.6 & 1 & 125 & \\
\hline panE & 14.3 & 1 & 96 & & 30.6 & $15.9 \%$ & 105 & $<0.0001$ & 10.7 & 1 & 140 & \\
\hline mdoH & 14.1 & 1 & 109 & & 28.2 & $6.7 \%$ & 113 & 0.029 & 11.8 & 1 & 146 & \\
\hline yjgB & 13.1 & 1 & 131 & & 28.2 & $11.3 \%$ & 109 & $<0.0001$ & 12.2 & 1 & 137 & \\
\hline elaA & 12.7 & 1 & 83 & & 30.1 & $14 \%$ & 105 & $<0.0001$ & 13.2 & 1 & 100 & \\
\hline $\mathrm{kdpB}$ & 15.6 & $11.9 \%$ & 140 & 0.0375 & 29.4 & $11.4 \%$ & 106 & $<0.0001$ & 12.6 & 1 & 99 & \\
\hline dcuC & 13.6 & 1 & 94 & & 28.7 & $8.8 \%$ & 118 & 0.0013 & 12.7 & I & 112 & \\
\hline muts & 11.3 & I & 69 & & 29.5 & $11.7 \%$ & 104 & $<0.0001$ & 12.2 & I & 94 & \\
\hline htrG & 13 & 1 & 112 & & 27.6 & 1 & 108 & & 12.4 & 1 & 140 & \\
\hline dhaH & 11.8 & 1 & 92 & & 29.4 & $11.3 \%$ & 111 & $<0.0001$ & 12.5 & I & 99 & \\
\hline $\operatorname{rimK}$ & 12.7 & 1 & 117 & & 30.2 & $14.4 \%$ & 108 & $<0.0001$ & 13.2 & 1 & 127 & \\
\hline gloB & 13.2 & I & 112 & & 29.2 & $10.8 \%$ & 109 & $<0.001$ & 12.4 & 1 & 94 & \\
\hline clpX & 15.9 & $14.4 \%$ & 96 & $<0.0001$ & 32.5 & $23 \%$ & 109 & $<0.0001$ & 12.6 & I & 79 & \\
\hline tufA & 12.7 & 1 & 123 & & 29.7 & $12.4 \%$ & 107 & $<0.0001$ & 12.6 & 1 & 87 & \\
\hline ybeA & 13.4 & I & 126 & & 28.1 & $6.6 \%$ & 110 & 0.02 & 13.2 & 1 & 82 & \\
\hline JW0632 & 13.4 & 1 & 119 & & 28.3 & $7.3 \%$ & 108 & 0.018 & 13.9 & 1 & 129 & \\
\hline $\mathrm{rfaD}$ & 14.8 & $6.2 \%$ & 128 & 0.45 & 30.9 & $16.9 \%$ & 106 & $<0.0001$ & 13.2 & 1 & 127 & \\
\hline yjiK & 13.1 & 1 & 123 & & 30.8 & $16.8 \%$ & 107 & $<0.0001$ & 12.3 & 1 & 105 & \\
\hline fdoH & 12.7 & 1 & 84 & & 28.6 & $8.3 \%$ & 110 & $<0.0001$ & 12.1 & 1 & 103 & \\
\hline yncA & 12.6 & 1 & 83 & & 31.2 & $18.2 \%$ & 106 & $<0.0001$ & 12.4 & 1 & 89 & \\
\hline fepB & 16.7 & $19.8 \%$ & 89 & $<0.0001$ & 32 & $21.3 \%$ & 90 & $<0.0001$ & 12.3 & 1 & 146 & \\
\hline hsdS & 14.9 & $7.3 \%$ & 112 & 0.0172 & 29.3 & $11 \%$ & 108 & $<0.0001$ & 13.4 & 1 & 128 & \\
\hline ygiQ & 13.8 & 1 & 108 & & 29.2 & $10.7 \%$ & 108 & $<0.0001$ & 12.8 & 1 & 56 & \\
\hline ung & 12.2 & 1 & 77 & & 29 & $9.7 \%$ & 110 & $<0.0001$ & 12 & 1 & 92 & \\
\hline hdfR & 14.7 & 1 & 141 & & 27.6 & 1 & 112 & & 12.8 & 1 & 135 & \\
\hline yjbD & 13 & 1 & 99 & & 29.4 & $11.3 \%$ & 112 & $<0.0001$ & 13.8 & $8.20 \%$ & 124 & $<0.0001$ \\
\hline fepC & 15.6 & $12.4 \%$ & 150 & $<0.0001$ & 31.5 & $19.3 \%$ & 106 & $<0.0001$ & 12.9 & 1 & 126 & \\
\hline hypE & 14.4 & 1 & 135 & & 26.8 & 1 & 98 & & 12.7 & I & 145 & \\
\hline JW5726 & 15.3 & $10.4 \%$ & 115 & 0.0125 & 26.9 & 1 & 103 & & 12.3 & 1 & 102 & \\
\hline ydhF & 14.3 & 1 & 205 & & 26.8 & 1 & 107 & & 12.2 & I & 113 & \\
\hline yqeH & 15.1 & $8.3 \%$ & 141 & 0.0266 & 25.6 & I & 98 & & 12.4 & I & 139 & \\
\hline yjgN & 14.3 & 1 & 101 & & 26.4 & 1 & 113 & & 12.2 & 1 & 150 & \\
\hline JW1321.5 & 13.4 & 1 & 135 & & 25.7 & 1 & 106 & & 12.3 & 1 & 142 & \\
\hline cyaA & 18.9 & $36.3 \%$ & 135 & $<0.001$ & 23.4 & 1 & 53 & & 13 & 1 & 144 & \\
\hline moaE & 15.5 & $12.2 \%$ & 116 & 0.0015 & 26 & 1 & 53 & & 12.2 & 1 & 90 & \\
\hline sufA & 14.7 & 1 & 129 & & 28.1 & $6.5 \%$ & 103 & $<0.0001$ & 12.5 & I & 105 & \\
\hline sufE & 15.2 & $9.4 \%$ & 133 & 0.02 & 27.4 & 1 & 105 & & 12.2 & 1 & 128 & \\
\hline yggX & 15.2 & $9.3 \%$ & 145 & 0.0137 & 26.3 & 1 & 107 & & 12.6 & 1 & 146 & \\
\hline yheM & 16.6 & $19.3 \%$ & 141 & $<0.0001$ & 28.3 & $7.3 \%$ & 104 & $<0.0001$ & 11.8 & I & 105 & \\
\hline yedR & 15.2 & $9.5 \%$ & 143 & 0.021 & 26.2 & 1 & 107 & & 12.3 & 1 & 84 & \\
\hline fepG & 14.4 & I & 83 & & 28.8 & $9 \%$ & 103 & $<0.0001$ & 11.8 & I & 139 & \\
\hline yicM & 15.9 & $14.2 \%$ & 146 & $<0.0001$ & 27.1 & 1 & 101 & & 12.6 & 1 & 139 & \\
\hline $\mathrm{dmsC}$ & 15.8 & $19.2 \%$ & 129 & $<0.0001$ & 23.3 & $8.8 \%$ & 103 & $<0.0001$ & 11.89 & 1 & 102 & \\
\hline yjgX & 14.8 & I & 179 & & 25.6 & I & 111 & & 12.3 & 1 & 144 & \\
\hline yrfD & 14.8 & 1 & 172 & & 27.4 & 1 & 110 & & 12.4 & 1 & 144 & \\
\hline srlA & 14.9 & 1 & 131 & & 22.2 & 1 & 72 & & 11.6 & 1 & 121 & \\
\hline pepA & 15.2 & $9.7 \%$ & 137 & 0.0119 & 25.7 & I & 110 & & 12.1 & 1 & 113 & \\
\hline yfaS & 13.2 & 1 & 97 & & 26.8 & 1 & 106 & & 12.5 & 1 & 128 & \\
\hline
\end{tabular}




\begin{tabular}{|c|c|c|c|c|c|c|c|c|c|c|c|c|}
\hline \multirow{2}{*}{$\begin{array}{l}\text { Gene } \\
\text { Knockout }\end{array}$} & \multicolumn{4}{|c|}{ N2 } & \multicolumn{4}{|c|}{ daf-2(e1370) } & \multicolumn{4}{|c|}{ daf-16(mu86); daf-2(e1370) } \\
\hline & Mean $^{a}$ & Change $^{b}$ & $\mathbf{n}^{\mathrm{c}}$ & $p$-Value ${ }^{\mathrm{d}}$ & Mean $^{\mathrm{a}}$ & change $^{b}$ & $\mathbf{n}^{\mathrm{c}}$ & $p$-Value ${ }^{\mathrm{d}}$ & Mean $^{a}$ & Change $^{b}$ & $\mathbf{n}^{\mathrm{c}}$ & p-Value ${ }^{\mathrm{d}}$ \\
\hline yjhc & 14.4 & I & 98 & & 28.2 & $6.9 \%$ & 108 & 0.0258 & 13.5 & $6.40 \%$ & 127 & 0.0039 \\
\hline tolA & 16.8 & $21.1 \%$ & 162 & $<0.0001$ & 27.7 & $5 \%$ & 107 & $<0.0001$ & 13.5 & $6.30 \%$ & 122 & $<0.0001$ \\
\hline ygjQ & 15.1 & $8.7 \%$ & 143 & 0.035 & 26.3 & 1 & 107 & & 12.7 & l & 127 & \\
\hline yqjH & 15.3 & $10 \%$ & 113 & 0.0074 & 26.6 & 1 & 107 & & 12.5 & 1 & 124 & \\
\hline
\end{tabular}

Table 2. Lifespans of $\boldsymbol{C}$. elegans strains fed on different bacterial mutants. Lifespan of C. elegans when feeding on bacterial knockouts: All experimental lifespan assays were performed in triplicate and survival data was grouped. Control lifespan assays performed at 2-3 different time points were done in triplicate and the

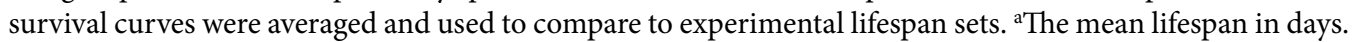
${ }^{b}$ The percent change of mean lifespan relative to K-12 control lifespan. ${ }^{c}$ The total number of individuals scored. ${ }^{\mathrm{d}}$ The $p$-value of log-rank test comparing survival curves of gene knockout fed to control strain fed worm.

Higher temperature has also been shown to enhance dauer formation ${ }^{31}$. We observed that at $27^{\circ} \mathrm{C}, \sim 56 \%$ of $\mathrm{N} 2$ animals grown on cyaA bacteria formed dauers, compared with only $20 \%$ dauers when grown on K12 bacteria (Fig. 3b, Table S1 and Fig. S4A). However, the dauer enhancement was rescued when cyaA bacteria were supplemented with $2 \mathrm{mM}$ cAMP. Next, we performed a dauer assay with daf-2(m41) mutant worms that make almost $100 \%$ dauer at semi-permissive temperature. We observed a $\sim 20 \%$ inhibition of dauer formation on the addition of cAMP $(2 \mathrm{mM})$ in daf-2(m41) mutant worms (Fig. S4B). In lifespan experiments, N2 worms fed on cyaA mutant bacteria displayed a $\sim 35 \%$ increase in lifespan. The addition of $2 \mathrm{mM}$ cAMP to cyaA bacteria significantly suppressed the lifespan extension observed in the cyaA mutant bacteria alone (Fig. 3c, Table S2 and Fig. S4C). Thus both the dauer and lifespan effects of $c y a A$ mutant bacteria could be rescued by exogenous addition of cAMP.

Bacterial cyaA mutant modulates dauer formation and lifespan through TGF- $\beta$ signaling and DAF-16 activation. To investigate the signaling mechanism by which $c y a A$ mutant bacteria modulates host C. elegans physiology to enhance dauer formation and extend lifespan, we examined the gene expression changes modulated by cyaA bacteria in control animals, using microarray profiling in adult animals fed cyaA bacteria and K12 bacteria (Fig. 4a and Table S3). Using GoMiner high-throughput analysis, we discovered multiple enriched biological processes within our data set (Fig. S5A). Of particular interest to us was the significant parent-child GO-term set of aging, multicellular organismal aging, and determination of adult lifespan. Comparison of changes in gene expression in the daf-2 background from previously published ${ }^{32}$ and our own data sets with transcriptionally altered genes in cyaA, showed considerable overlap (Fig. S5B,C). Collectively, these data suggest that feeding cyaA mutant $E$. coli activates DAF-16 to enhance dauer formation and extend lifespan.

We then examined the mechanism of activation of DAF- 16 by measuring the expression of genes upstream of DAF-16 known to be involved in dauer formation. We observed that $d a f-7$, a gene encoding a TGF- $\beta$-like ligand, was down-regulated in control worms grown on cyaA bacteria. To confirm this, we examined the expression of mRNA of $d a f-7$ by RT-PCR in one-day adult control animals on cyaA mutant bacteria, compared with animals fed with K-12 or cyaA supplemented with cAMP $(2 \mathrm{mM})$. DAF-7 expression was significantly reduced $(\sim 50 \%)$ on feeding animals with cyaA mutant bacteria and was rescued by addition of cAMP $(2 \mathrm{mM})$ to the bacterial lawns (Fig. 4b). We also examined DAF-7::GFP expression in the ASI chemosensory neuron in L1 and L2 when fed with cyaA mutant bacteria. We observed that cyaA mutant bacteria inhibited the expression DAF-7::GFP in L1 and L2 stage in comparison to K-12 bacteria (Fig. 4c,d). Conversely, supplementation with 2 mM exogenous cAMP to cyaA mutant bacteria increased the expression of DAF-7 in a fraction of L1 and L2 animals (Fig. 4c,d). These results suggest that cAMP levels in the bacteria can modulate the expression of DAF-7 in worms, which influences dauer formation and insulin signaling ${ }^{33}$.

To further examine how cyaA mutant bacteria and cAMP modulate dauer formation we carried out epistasis analysis on C. elegans mutants using mutants in the three major pathways involved in dauer formation ${ }^{16,17,34}$. As shown in Fig. 3 dauer entry in daf-2(1370) mutants, was significantly increased when fed on cyaA mutant bacteria but was reversed by addition of exogenous cAMP. However, neither the daf-7(e1372) mutant, which is defective in TGF- $\beta$ signaling nor the daf-11(m47) mutant, which has defective cyclic GMP signaling and is involved in DAF-7 secretion, showed any enhancement of dauer formation when fed on cyaA mutant bacteria (Fig. $5 \mathrm{a}-\mathrm{c}$ and Table S1). This data supports the hypothesis that reduced bacterial cAMP enhances dauer formation by a similar mechanism as inhibition cGMP and TGF- $\beta$ signaling pathways in worms.

The constitutive dauer formation phenotype of daf-7(e1372), but not daf-2(e1370), is suppressed by mutations in daf-7 downstream factors daf-3 and daf- $5^{2}$. The introduction of either daf-3(e1376) or daf-5(e1386) into the daf-2(e1370) background prevented cyaA mutant bacteria from enhancing dauer formation (Fig. $5 \mathrm{~d}-\mathrm{e}$ and Table S1). This suggests that cyaA mutant bacteria acts through TGF- $\beta$ signaling to activate DAF- 16 , and enhancing dauer formation. We confirmed our finding from the screen that worms fed on cyaA mutant bacteria show increased nuclear localization of DAF-16 (Fig. 5f). Furthermore, not only was the nuclear localization of DAF16::GFP enhanced on cyaA mutant bacteria compared with the K12 control, but it was also reversed upon supplementation of bacterial lawns with exogenous cAMP (Fig. 5f).

Conserved molecular pathways that regulate dauer formation like Insulin/IGF-1 signaling (IIS) and TGF- $\beta$ signaling pathways also regulate longevity. This also appears to be the mechanism by which cyaA bacteria extend lifespan, since cyaA bacteria did not extend lifespan in either the daf-7(e1372) or the daf-11(m47) mutant backgrounds, nor did it extend lifespan in daf-2(e1370); daf-3(e1376) or daf-2(e1370); daf-5(e1386) double mutant 
a

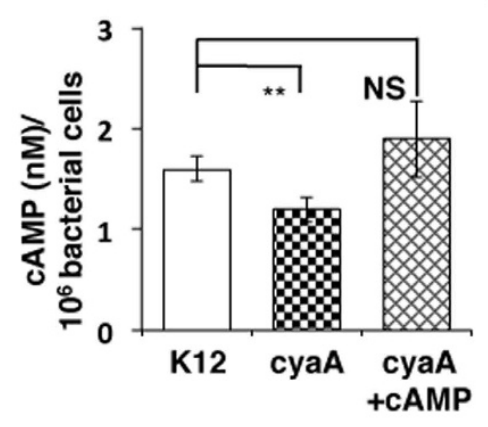

b

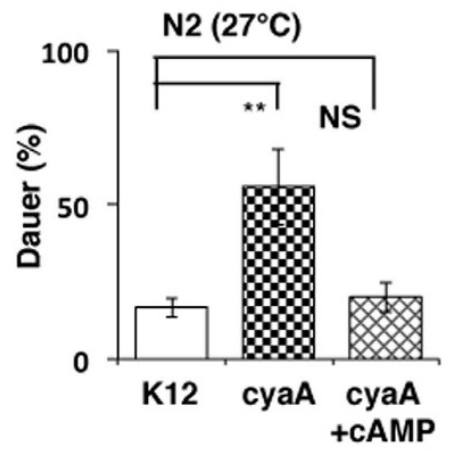

C

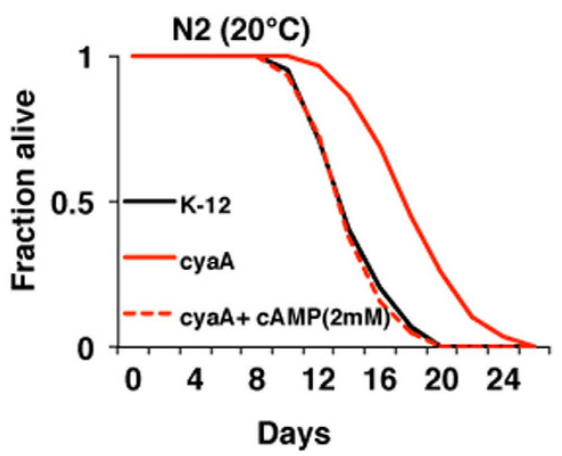

Figure 3. Feeding bacterial cyaA mutants modulates lifespan and dauer formation in C. elegans. (a) The amount of cAMP in K-12 (control), mutant cyaA bacteria, cyaA mutant bacteria supplemented with cAMP ( $2 \mathrm{mM})$, (b) Bacterial knockout of cyaA enhances the dauer formation in $\mathrm{N} 2$ strain. Control (N2) animals fed on K-12 (control) bacteria, mutant cyaA bacteria and cyaA mutant bacteria supplemented with cAMP (2 mM) on minimal media agar plate. Data is represented as mean percent $\pm S D$ of greater than 3 biological replicates, $\mathrm{n}>200$. (c) Feeding E. coli cyaA mutants extends the lifespan of N2 strain in C. elegans. ${ }^{* * *} P<0.0001$.

a

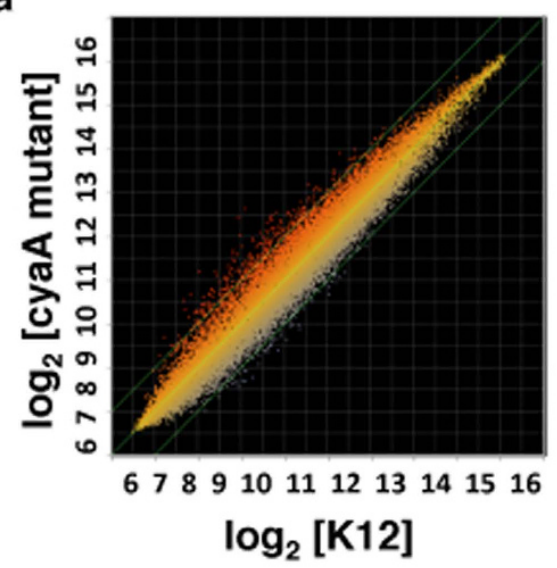

C

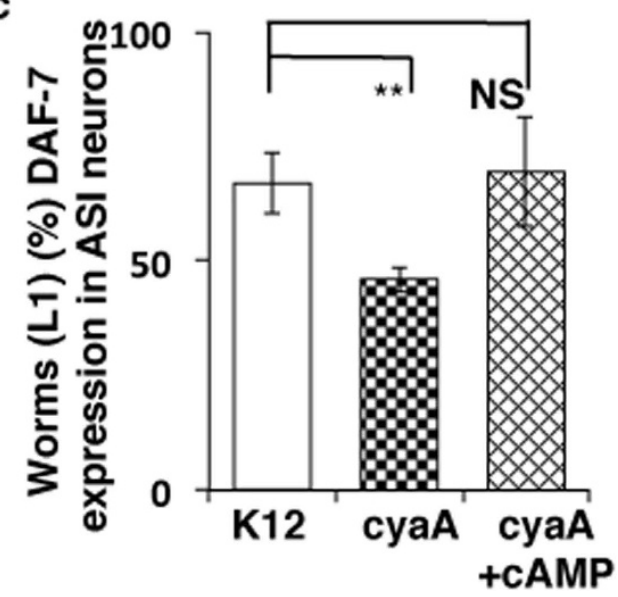

b

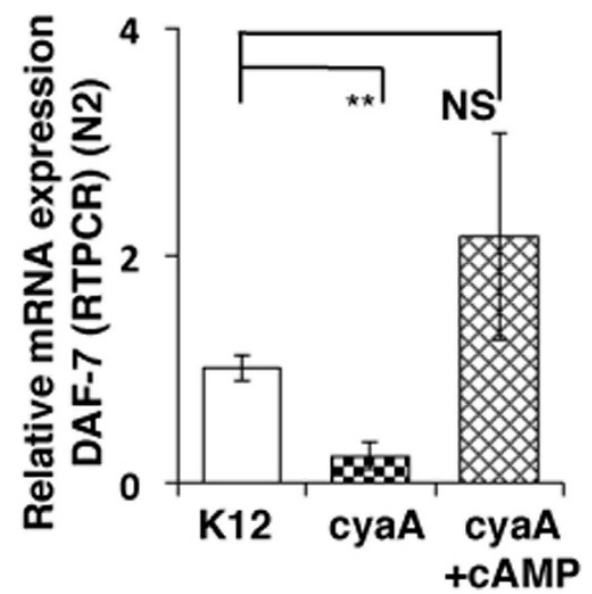

d

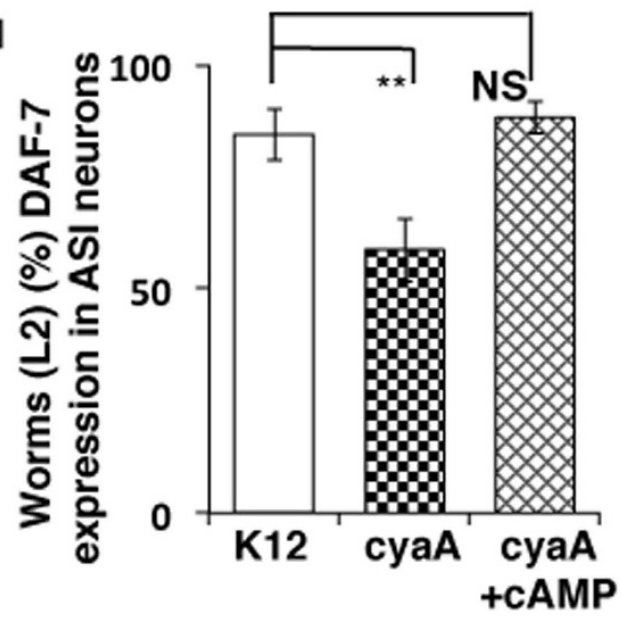

Figure 4. Feeding bacterial cyaA mutants alters DAF-7 expression in C. elegans. (a) A scatter plot of log2 transcript probe intensities for daf-2(e1370) versus N2, and K-12 (control) versus cyaA fed control worm comparisons. Genes which show only p-values of $<0.05$ and fold changes $>1.3$ and $<0.8$ were shortlisted.

(b) Relative expression of daf-7 mRNA in N2 animals on feeding K-12(control), cyaA mutant bacteria, and cyaA mutant bacteria supplemented with cAMP $(2 \mathrm{mM})$. (c,d) cAMP induces the expression of DAF-7 in ASI neuron. The fraction of animals show DAF-7 expression at L1 and L2 stage on feeding K-12 (control), cyaA mutant bacteria, and cyaA mutant bacteria supplemented with cAMP $(2 \mathrm{mM})$. The data is represented as percent mean \pm S.D. of greater than 3 biological replicates, $n>200,{ }^{* *} \mathrm{P}<0.0001$. 

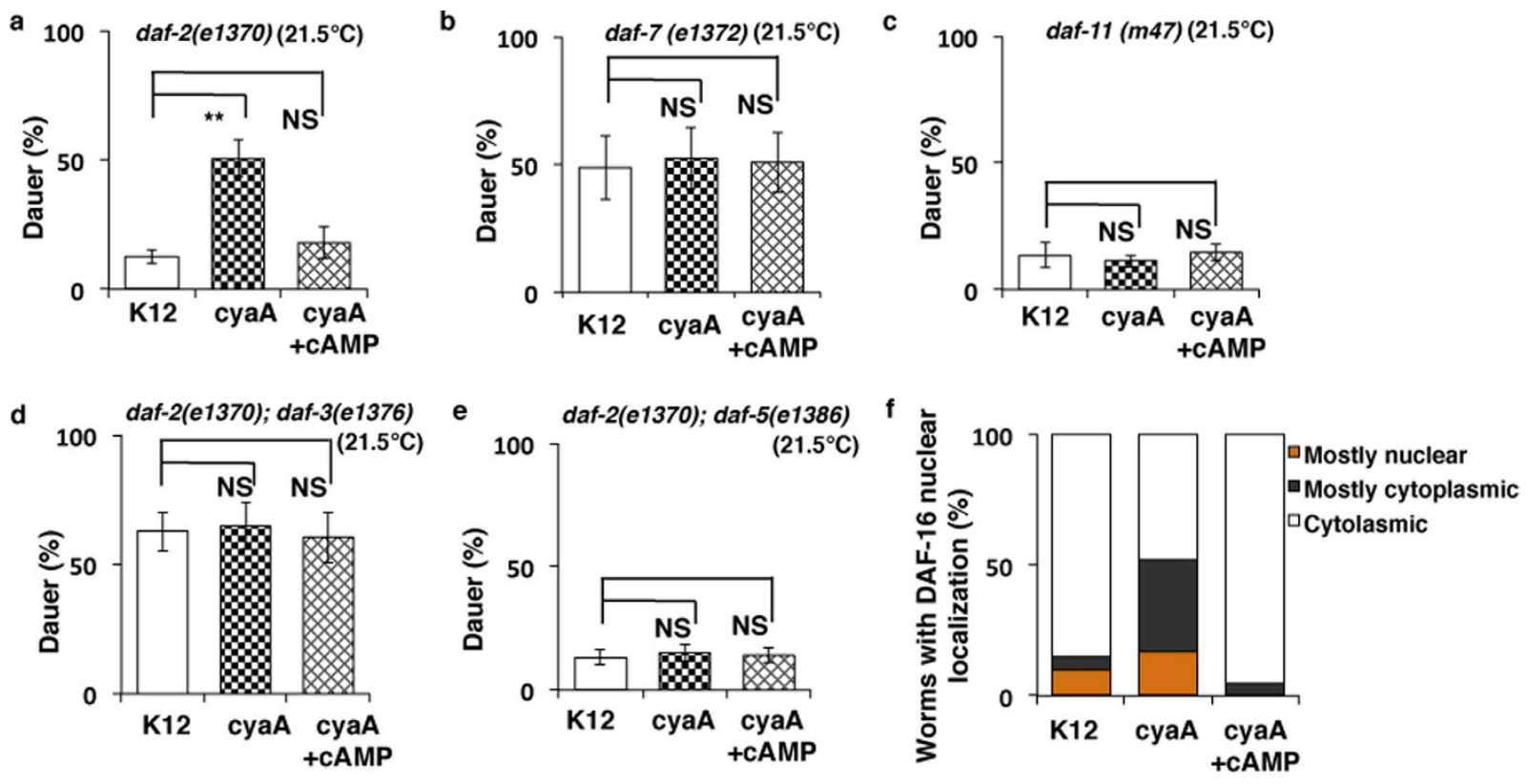

Figure 5. Bacterial $c y a A$ mutants affect dauer formation through TGF- $\beta$ pathway and DAF-16. (a-e) Dauer formation of daf-2(e1370), daf-7(e1372), daf-11(m47) and daf-2(e1370); daf-3(e1376), daf-2(e1370); daf5(e1386) animals on feeding K-12 (control), cyaA mutant bacteria, and cyaA mutant bacteria supplemented with cAMP (2 mM). (f) DAF-16::GFP worms in the N2 background on feeding K-12( control), cyaA mutant bacteria, and $c y a A$ mutant bacteria supplemented with cAMP $(2 \mathrm{mM})$. Quantification of DAF-16::GFP localization on feeding K-12 (control), cyaA mutant bacteria, and cyaA mutant bacteria supplemented with $\operatorname{cAMP}(2 \mathrm{mM})$. In each case, the data is represented as mean percent $\pm S$.D of three replicates, ${ }^{\star *} P<0.0001$, $\mathrm{n}>200$.

backgrounds (Fig. 6a-f and Table S2). Together, these data indicates that reduced bacterial cAMP acts via the TGF- $\beta$ signaling pathway to enhance DAF-16 resulting in increased dauer formation and lifespan.

\section{Discussion}

The type of bacterial food source modulates C. elegans development and lifespan ${ }^{35-44}$. In this study, we have screened for bacterial mutants that regulate dauer formation in C. elegans to understand the role of bacterial genes in modulating nutrient sensing pathways. We used the Keio mutant E. coli library ${ }^{15}$ to identify individual gene knockout mutants that affect bacterial signals that enhance dauer formation in C. elegans. Genes mutated among the bacterial mutants identified in the dauer screen have varied functions (Fig. 1b) including, metabolism, translation, biogenesis of membrane and DNA replication (Fig. $1 \mathrm{~b}$ and Table 1). These results suggest that bacteria act not only as a food source but also provide signals that influence nutrient signaling pathways in C. elegans. A better understanding of $E$. coli genes that influence these signaling pathways could give us a better understanding of complex host-bacterial relationships in other species.

In the absence of bacterial food, C. elegans show reduced rates of growth and progeny production and lifespan extension ${ }^{45}$. These observations can be explained by the idea that worms subjected to suboptimal nutrition or the absence of toxic or pathogenic components of bacteria, extend lifespan. Previously, different bacterial diets ${ }^{10}$, and bacterial metabolites like folate ${ }^{36}$ and fatty acids ${ }^{14}$ have been proposed to modulate lifespan. Our results identify several bacterial genes that are involved in the production or transport of various downstream metabolites to regulate dauer formation and lifespan in worms. Furthermore, we observed that the worms fed on dead bacteria show increase in dauer formation (Fig. S5D), which suggests that viable secondary metabolites can have a profound effect on bacterial physiology that can modulate dauer formation in worms. To further examine if the cAMP-mediated dauer rescue was due to the direct uptake of cAMP by the worm, or an indirect effect on bacterial metabolism, we grew worms on UV-killed bacteria supplemented with cAMP. In these experiments, we found that there was an increase in basal dauer formation in both the K12 and cyaA controls, but that the addition of cAMP to UV-killed cyaA bacteria did not significantly reduce the dauer entry phenotype (Fig. S5D). These experiments suggest that action of cAMP requires live bacteria to mediate its effects on dauer formation.

There are several pathways involved in dauer formation, including guanylyl cyclase, ILS, and TGF- $\beta^{2}$. A critical downstream factor of some of these pathways is DAF-16 which has been shown to integrate inputs from various upstream dauer formation pathways ${ }^{2,46}$. Most of the bacterial mutants that enhance dauer formation from our screen do not extend lifespan in daf-16 null mutant animals and enhance nuclear localization of DAF-16 to a variable extent (Fig. 2). These bacterial mutants also enhance the expression of SOD-3, a direct target of DAF-16 ${ }^{47,48}$. These data suggest that several but not all of these bacterial mutants require DAF-16/FOXO for increased longevity and improved health span, implicating bacterial metabolites in modulating nutrient sensing signaling pathways ${ }^{49}$. 

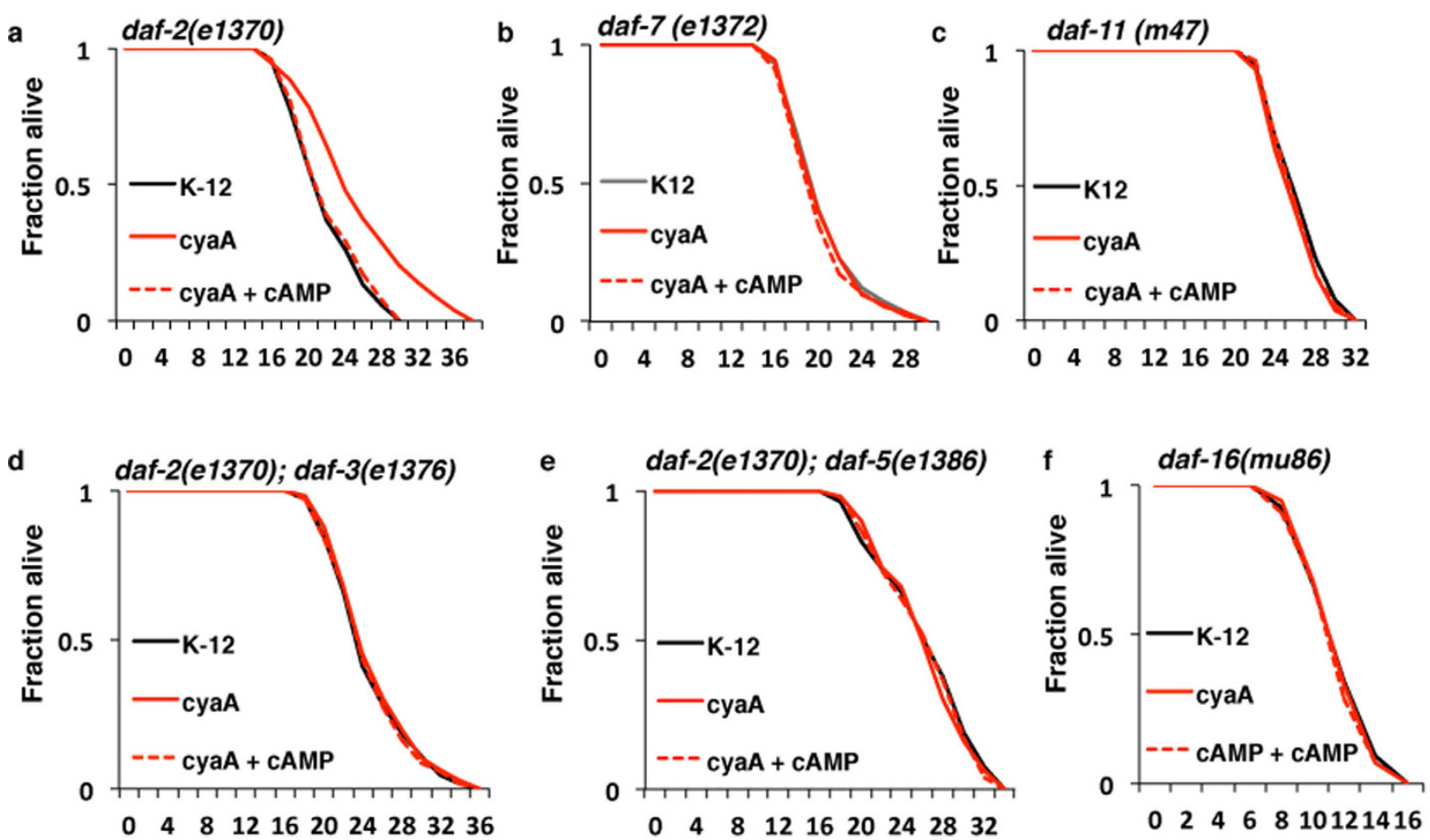

Figure 6. Bacterial cyaA mutants affect lifespan through TGF- $\beta$ pathway and DAF-16. (a-f) Kaplan-Meier survival curves of synchronously aging hermaphrodite worms: daf-2(e1370), daf-7(e1372), daf-11(m47), daf-2(e1370); daf-3(e1376), daf-2(e1370); daf-5(e1386) and daf-16(mu86) animals fed on K-12 (control), $c y a A$ mutant bacteria, and cyaA mutant bacteria supplemented with $\mathrm{cAMP}(2 \mathrm{mM}) . \mathrm{n}=100,{ }^{* *} \mathrm{p}<0.01$; average \pm std. $\operatorname{dev}(\mathrm{n}=3)$.

We also identified that bacteria deficient in $c y a A$ inhibit TGF- $\beta$ signaling to enhance DAF-16/FOXO to enhance dauer formation and lifespan. Dauer assays using daf-7 and daf-11 null mutants suggests that the effects of feeding on the cyaA mutant bacteria on dauer formation require TGF- $\beta$ and the guanylyl cyclase (DAF-11) expression $^{2,27,46}$. DAF-11 is localized primarily in the ciliary endings of some of the amphid neurons and integrates environmental signals from G-protein coupled receptors (GPCR) ${ }^{50}$. As mentioned before, ILPs and DAF-7 are expressed and released primarily by neurons and ASI neurosensory cells, respectively ${ }^{16}$. Thus we speculate that $c y a A$ mutant bacteria differentially impact these sensory neurons to regulate changes in dauer formation and lifespan. We speculate that this regulation may be carried out by reducing cAMP levels produced by the E. coli, resulting in changes in secondary metabolites or cAMP itself ${ }^{29}$. Based on our observation it appears that feeding cyaA mutant bacteria modulates DAF-11 signaling, decreasing DAF-7 neuronal expression (Fig. 7). Further studies are required to uncover the cross talk between $c y a A$ dependent bacterial products on $C$. elegans signaling pathways.

Bacterial products as part of the gut microbiome affect many biological processes such as metabolism, longevity, and health span in mammals ${ }^{16,35}$. The function of some of these bacteria has been well described in several human diseases including obesity, liver diseases, metabolic syndrome, autoimmune disorders, and diabetes ${ }^{51-53}$. Some of these microbiome related products modulate diverse host metabolic activities resulting in pathologies related to insulin sensitivity ${ }^{54,55}$. However, the mechanisms by which individual bacterial gene products interact with the host to modulate insulin signaling pathways are not known ${ }^{49}$. Gut microbiome's influence on biological processes has been observed across different species from insects to mammals. In this study, we describe how mono-association of bacterial mutants with $C$. elegans can help decipher how specific bacterial signals modulate host physiology. Thus interaction between bacteria and C. elegans can be used to understand conserved signals that are likely to play a role in host-microbiome interactions in humans which may influence diseases like Type II diabetes and obesity.

\section{Methods}

C. elegans strains and growth conditions. All strains were obtained from the Caenorhabditis Genetics Center (CGC). The strains obtained from the CGC were outcrossed 6 times to N2 (control) worms. Strains used in this manuscript from CGC are: CB1370 daf-2(e1370) III, CB1372 daf-7(e1372) III, DR47 daf-11(m47) V, CF1038 daf-16(mu86) I, HT1608 daf-2(e1370) III; daf-3(e1376) X,CF1553 muIs84 [(pAD76) sod-3p::GFP + rol-6(su1006)], DR1624 daf-5(e1386) II; daf-2(e1370) III, CF1139 muIs61 [(pKL78) daf16::GFP + rol-6(su1006)], DR1564 daf-2 (m41) III, FK181 ksIs2 [daf-7p::GFP + rol-6(su1006)], TM151 sod-2(sj173) I; daf-2(e1370) III; sod-3(sj134) $X$ and PR678 tax-4(p678) III; daf-11(m47) $V^{56}$. Strains were maintained on nematode growth media plates at 


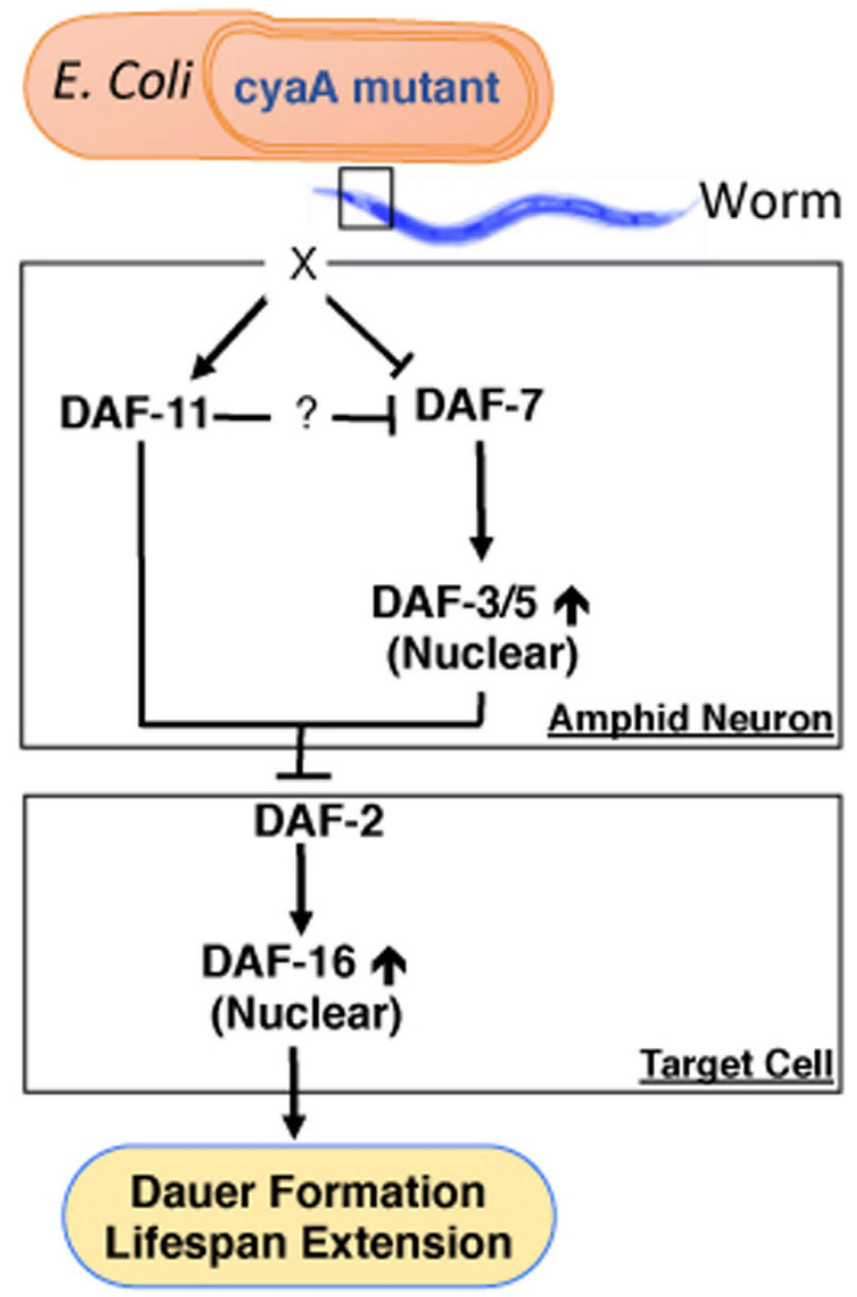

Figure 7. Model of how bacterial cAMP signaling regulates dauer formation and lifespan in worms. Lack of bacterial cAMP inhibits the expression of DAF-7, resulting in the inhibition of DAF-3/5. This leads to the suppression of IGF-1 pathway in animals, and enhances the dauer formation and lifespan extension in DAF-16/ FOXO dependent manner.

$20^{\circ} \mathrm{C}$ seeded with E. coli (K12) bacteria grown in Luria broth. For egg collection, gravid adults were soaked in hypochlorite solution as described previously ${ }^{57}$.

E. coli strains. E. coli mutant strains, including the parent $K 12$ BW25113 strain, were obtained from the Keio mutant collection ${ }^{15}$. The strain library was shipped and stored as a frozen stock in 96 -well plates. Stock plates were pin-replicated to produce a working copy plate containing Luria Broth (LB) and $25 \mu \mathrm{g} / \mathrm{ml}$ kanamycin. For assays used in this study, E. coli strains were stab cultured and grown overnight with shaking at $37^{\circ} \mathrm{C}$ in minimal media as described below. Overnight cultures were seeded on minimal media plates and dried at $37^{\circ} \mathrm{C}$ for 12 hours prior to transfer of C. elegans.

Media. Luria broth (LB) and nematode growth media (NGM) were used to maintain stock cultures of $E$. coli and C. elegans strains, respectively. Minimal media was used for assays in this study as described previously ${ }^{58}$. Liquid media for bacterial growth contained: $0.05 \mathrm{M} \mathrm{NaCl}, 0.04 \mathrm{M} \mathrm{NH}_{4} \mathrm{Cl}, 0.01 \mathrm{M} \mathrm{CaCl}_{2}, 0.025 \mathrm{M}$ phosphate buffer, $0.4 \%$ glucose, $1 \mu \mathrm{g} / \mathrm{mL}$ thiamine, and $0.001 \mathrm{M} \mathrm{MgSO}_{4}$. Minimal media plates for subsequent $C$. elegans experiments contained: $2 \%$ agar, $0.05 \mathrm{M} \mathrm{NaCl}, 0.04 \mathrm{M} \mathrm{NH}_{4} \mathrm{Cl}, 0.001 \mathrm{M} \mathrm{CaCl}_{2}, 1 \mu \mathrm{g} / \mathrm{mL}$ cholesterol, $0.025 \mathrm{M}$ phosphate buffer, $0.4 \%$ glucose, $1 \mu \mathrm{g} / \mathrm{mL}$ thiamine, and $0.001 \mathrm{M} \mathrm{MgSO}_{4}$. All compounds supplemented to the agar plates for rescue experiments were purchased from Sigma-Aldrich.

PCR confirmation. Bacterial strains for kanamycin cassette confirmation were streaked onto LB plates containing $25 \mu \mathrm{g} / \mathrm{ml}$ kanamycin. Strains were colony purified, and genomic PCR was performed. The primer sets were designed for individual knockout strains around the outside of the target gene. The forward primer was designed to be within $200 \mathrm{bp}$ upstream of the $5^{\prime}$ end, and the reverse primer was within $200 \mathrm{bp}$ downstream of the $3^{\prime}$ end of the target gene. The thermal cycler parameters were as follows: initial $5 \mathrm{~min}$ at $94^{\circ} \mathrm{C}$, then 25 cycles of 
$30 \mathrm{~s}$ at $94^{\circ} \mathrm{C}, 10 \mathrm{~s}$ at $56^{\circ} \mathrm{C}, 1 \mathrm{~min}$ at $72^{\circ} \mathrm{C}$, and final $5 \mathrm{~min}$ at $72^{\circ} \mathrm{C}$. Products were run on an agarose gel and amplified products were examined for appropriate length. Representative list of primers $\left(5^{\prime}\right.$ to $\left.3^{\prime}\right)$.

\begin{tabular}{|l|l|l|}
\hline For all the mutants & Forward & ATCGCCTTCTATCGCCTTCTTAGC \\
\hline clpX & Reverse & CAGAGAGCGCAGAAATACGCGCG \\
\hline dmsC & Reverse & CCATCGGCGTCCAGATGCTG \\
\hline cyaA & Reverse & CGAAATGCACCACCTGATTG \\
\hline pepA & Reverse & GAGAATCTTCATAAGGAACG \\
\hline yjhC & Reverse & GGACGCATGAAGAACGTCAG \\
\hline ybeA & Reverse & GCACATCTTCATAGTAACGC \\
\hline elaA & Reverse & CGTTGTGCCTGGTCCAACG \\
\hline htrG & Reverse & CGCGCAGTACCTGGAAGAAC \\
\hline yjbD & Reverse & GACTCCCAGGGGCTGATTTTCC \\
\hline hsdS & Reverse & CTGCAAAATCAGACTGGTAA \\
\hline panE & Reverse & GCTGTGGTGTGAGCGCGGGGTGATG \\
\hline moaD & Reverse & GCGGTCAGCAACAAGCCAACGG \\
\hline rfaD & Reverse & GCCCGCTTCATGATCTTTCGCC \\
\hline gloB & Reverse & GACCCGACCTTCGCCGCTG \\
\hline rimK & Reverse & GCCAAATCGACACAAGAGAAG \\
\hline ygiQ & Reverse & CGACTCTTACCGCCAGGCG \\
\hline laR & Reverse & GGGGAAAACGTCTTAAATACTC \\
\hline yjiK & Reverse & GATGGCGTGTTTTTTCGAGGGC \\
\hline dcuC & Reverse & GGCGCAGGCCCGAATGATGATCG \\
\hline
\end{tabular}

RT-PCR validation. Quantitative real-time PCR was carried out using SYBR Green I (Sigma Aldrich) assay reagents to verify gene expression profiles. $200 \mathrm{\eta g}$ of total RNA were reverse transcribed to cDNA and the real-time PCR reactions were performed on a 7500 Fast System Real-Time PCR cycler (Applied Biosystems, Foster City, CA), according to the manufacturer's instructions. The gene expression fold changes between different treatment groups were calculated using the delta Ct method ${ }^{59}$.

\begin{tabular}{|l|l|l|}
\hline daf -7 & Forward & TCAGCATTCAACTTCCAATTGATAC \\
\hline & Reverse & TCAGCATTCAACTTCCAATTGATAC \\
\hline act5 & Forward & GTCATCAAGGAGTCATGGTC \\
\hline & Reverse & TTCTCCATATCATCCCAGTT \\
\hline
\end{tabular}

Dauer assay. Dauer assay using bacterial mutants. Bacterial strains were grown to stationary phase in minimal medium prior to being seeded on minimal media agar. Mutant and control $E$. coli plates were left to grow overnight at $37^{\circ} \mathrm{C}$. Eggs were placed on plates containing the $E$. coli mutants. Plates were incubated at $21.5^{\circ} \mathrm{C}$ for 4-5 days prior to assessing dauer or non-dauer state worms. Worm larval states were analyzed using a dissecting microscope and manually counted.

Measurement of cAMP. cAMP levels from bacterial strains and worm strains were measured using the cAMP- Glo TM assay kit purchased from Promega (Madison, WI). For bacteria, $5 \mathrm{ml}$ cultures of K-12, cyaA were grown with or without the presence of cAMP $(2 \mathrm{mM})$ in minimal media at $37^{\circ} \mathrm{C}$ for overnight. Cells were counted in $50 \mu \mathrm{l}$ bacterial culture and were sonicated for complete lysis, and $5 \mu \mathrm{l}$ of the lysate was used to measure cAMP. The number of bacteria was counted with standard bacterial colony count protocol and the amount of cAMP in different bacteria was expressed per $10^{6}$ bacterial cells. PBS for complete lysis. $5 \mu l$ sample of the lysate was used for cAMP measurement, and the amount of cAMP was expressed per 200 animals.

Fluorescence Microscopy. Age-synchronized L1-stage animals carrying DAF-16::GFP integrated transgenes (daf-16( $m g D f 47) \mathrm{I})$ were placed on plates seeded with overnight cultures of bacterial strains as described above. Animals were grown at $15^{\circ} \mathrm{C}$ for $2-3$ days and then moved to $21.5^{\circ} \mathrm{C}$ for one day unless otherwise noted. The fluorescent images were captured using reflected light fluorescence microscopy (Olympus IX3) and the images were then processed for densitometry analysis using ImageJ.

Lifespan assay. Late L4 larvae growing at $15^{\circ} \mathrm{C}$ were transferred to fresh minimal media plates with FUdR $(5 \mu \mathrm{g} / \mathrm{ml})$ added to the bacterial lawn as indicated in the results. The first day of adulthood is day 1 in survival curves. Animals were scored as alive, dead or lost every other day. Animals that failed to display touch-provoked movement were scored as dead. Animals that died from causes other than aging, such as sticking to the plate walls, internal hatching or bursting in the vulval region, were scored as lost. Animals were transferred to fresh plates and fresh E. coli every 2 days with cAMP added to have final concentration $2 \mathrm{mM}$. Plates were dried for 
15 minutes at $20^{\circ} \mathrm{C}$ before the worms were transferred. All lifespan experiments were performed at $21.5^{\circ} \mathrm{C}$. Survival curves were plotted, and statistical analyses (log-rank tests) were performed using Prism 4 software (Graphpad Software, Inc., San Diego, CA, USA). Statistical significance between lifespan curves was determined by p-value of $<0.05$ and a mean lifespan of $>5 \%$ difference compared to the control mean as described before ${ }^{32,60}$.

Behavioral assays: Pharyngeal pumping and body bends. Worms were observed using stereomicroscope at 40x magnification. Pumps per minute were counted as described previously ${ }^{61}$. Body bends per minute were counted as described previously ${ }^{62}$.

Bacterial choice assay. Age-synchronized day 1 adult worms were used. Minimal media plates were used for this assay: $2 \%$ agar, $0.05 \mathrm{M} \mathrm{NaCl}, 0.04 \mathrm{M} \mathrm{NH}_{4} \mathrm{Cl}, 0.001 \mathrm{M} \mathrm{CaCl}_{2}, 5 \mu \mathrm{g} / \mathrm{mL}$ cholesterol, $0.025 \mathrm{M}$ phosphate buffer, $0.4 \%$ glucose, $1 \mu \mathrm{g} / \mathrm{mL}$ thiamine, and $0.001 \mathrm{M} \mathrm{MgSO}_{4}$. Overnight bacterial culture with OD $600 \mathrm{~nm}$ of 2.0 was spotted $(30 \mu \mathrm{l})$ equidistant from the center of the plate and dried for 15 minutes at $37^{\circ} \mathrm{C}$. Both $\mathrm{K} 12$ and mutant bacteria had approximately the same cellular density: K12 bacteria at $0.8 \times 10^{7} \pm 1.2 \times 10^{7}$ colony-forming units (cfu) per ml and dmsC mutant bacteria at $0.7 \times 10^{7} \pm 1.3 \times 10^{7}$ colony-forming units (cfu) per ml. Worms were washed and prepared as previously described ${ }^{63}$. The worms were placed in the center of the plate, and positions of the worms were observed using stereomicroscope and images taken at 15 minutes interval. Percentage of worms at each lawn at $(1 \mathrm{hr})$ were plotted as a histogram.

C. elegans feeding behaviour assays. Feeding behavior was assessed based on bacteria depletion as described before ${ }^{64}$. Minimal media plates were used for this assay: $2 \%$ agar, $0.05 \mathrm{M} \mathrm{NaCl}, 0.04 \mathrm{M} \mathrm{NH}_{4} \mathrm{Cl}, 0.001 \mathrm{M}$ $\mathrm{CaCl}_{2}, 5 \mu \mathrm{g} / \mathrm{mL}$ cholesterol, $0.025 \mathrm{M}$ phosphate buffer, $0.4 \%$ glucose, $1 \mu \mathrm{g} / \mathrm{mL}$ thiamine, and $0.001 \mathrm{M} \mathrm{MgSO}_{4}$. Overnight bacterial culture with OD $600 \mathrm{~nm}$ of 0.8 was spotted $(60 \mu \mathrm{l})$ in center of the plate with streotomycin $(300 \mathrm{ng} / \mathrm{ml})$, carbenicillin \& Kanamycin $(50 \mu \mathrm{g} / \mathrm{ml})$, and FUdR $(5 \mu \mathrm{g} / \mathrm{ml})$ and the plates were dried for $15 \mathrm{~min}-$ utes at $37^{\circ} \mathrm{C}$. Age synchronized late $\mathrm{L} 4$ worms $(n=60)$ were washed and prepared as previously described ${ }^{63,64}$ and introduced on the plates. The worms were left on the plates overnight at $20^{\circ} \mathrm{C}$. Control plates with bacteria spotted as described above with no worms were also incubated at $20^{\circ} \mathrm{C}$ overnight. After $24 \mathrm{hrs}$ the bacteria was washed off the plates and checked for OD at $600 \mathrm{~nm}$.

Lawn leaving assay. Age-synchronized day 1 adult animals $(n=20$ per plate) were transferred to bacterial lawns cultured under conditions described above. Assay was performed for 5 minutes and lawn leaving events were manually counted by observing under the microscope and averaged to lawn leaving events per minute as previously described ${ }^{65}$.

Statistical Analysis. Microarray data analysis was performed using SPSS Professional Edition software (IBM). Descriptive statistics including mean and s.e.m. along with one-way ANOVAs followed by multiple comparison tests and two-tailed T-test were used to determine significant differences. $\mathrm{P}<0.05$ was considered significant as described before ${ }^{32,66}$. For lifespan assays, log-rank tests were performed by the Prism 4 software as described before ${ }^{32,60}$. Pearson product-moment correlation coefficient was calculated to measure the correlation between data sets.

\section{References}

1. Hashmi, S. et al. A C. elegans model to study human metabolic regulation. Nutr Metab (Lond) 10, 31, doi: 10.1186/1743-7075-10-31 (2013).

2. Hu, P. J. Dauer. WormBook: the online review of C. elegans biology 1-19, doi: 10.1895/wormbook.1.144.1 (2007).

3. Golden, J. W. \& Riddle, D. L. ACaenorhabditis elegans dauer-inducing pheromone and an antagonistic component of the food supply. J Chem Ecol 10, 1265-1280, doi: 10.1007/BF00988553 (1984).

4. Golden, J. W. \& Riddle, D. L. A pheromone influences larval development in the nematode Caenorhabditis elegans. Science 218, 578-580 (1982)

5. Butcher, R. A., Ragains, J. R., Kim, E. \& Clardy, J. A potent dauer pheromone component in Caenorhabditis elegans that acts synergistically with other components. Proceedings of the National Academy of Sciences of the United States of America 105, 14288-14292, doi: 10.1073/pnas.0806676105 (2008).

6. Ludewig, A. H. \& Schroeder, F. C. Ascaroside signaling in C. elegans. WormBook: the online review of C. elegans biology, 1-22, doi: 10.1895/wormbook.1.155.1 (2013).

7. Balla, K. M. \& Troemel, E. R. Caenorhabditis elegans as a model for intracellular pathogen infection. Cellular microbiology 15, 1313-1322, doi: 10.1111/cmi.12152 (2013).

8. Beale, E., Li, G., Tan, M. W. \& Rumbaugh, K. P. Caenorhabditis elegans senses bacterial autoinducers. Appl Environ Microbiol 72, 5135-5137, doi: 10.1128/AEM.00611-06 (2006).

9. Ben Arous, J., Laffont, S. \& Chatenay, D. Molecular and sensory basis of a food related two-state behavior in C. elegans. PloS one 4, e7584, doi: 10.1371/journal.pone.0007584 (2009).

10. Avery, L. \& You, Y. J. C. elegans feeding. WormBook 1-23, doi: 10.1895/wormbook.1.150.1 (2012).

11. Larsen, P. L., Albert, P. S. \& Riddle, D. L. Genes that regulate both development and longevity in Caenorhabditis elegans. Genetics 139, 1567-1583 (1995).

12. Riddle, D. L., Swanson, M. M. \& Albert, P. S. Interacting genes in nematode dauer larva formation. Nature 290, 668-671 (1981).

13. Ogg, S. et al. The Fork head transcription factor DAF-16 transduces insulin-like metabolic and longevity signals in C. elegans. Nature 389, 994-999, doi: 10.1038/40194 (1997).

14. Kaul, T. K., Reis Rodrigues, P., Ogungbe, I. V., Kapahi, P. \& Gill, M. S. Bacterial fatty acids enhance recovery from the dauer larva in Caenorhabditis elegans. PloS one 9, e86979, doi: 10.1371/journal.pone.0086979 (2014).

15. Baba, T. et al. Construction of Escherichia coli K-12 in-frame, single-gene knockout mutants: the Keio collection. Mol Syst Biol 2, 2006 0008, doi: 10.1038/msb4100050 (2006)

16. Barna, J. et al. Heat shock factor-1 intertwines insulin/IGF-1, TGF-beta and cGMP signaling to control development and aging. BMC developmental biology 12, 32, doi: 10.1186/1471-213X-12-32 (2012).

17. Cassada, R. C. \& Russell, R. L. The dauerlarva, a post-embryonic developmental variant of the nematode Caenorhabditis elegans. Dev Biol 46, 326-342 (1975). 
18. Vowels, J. J. \& Thomas, J. H. Genetic analysis of chemosensory control of dauer formation in Caenorhabditis elegans. Genetics 130, $105-123$ (1992).

19. al-Waiz, M., Mikov, M., Mitchell, S. C. \& Smith, R. L. The exogenous origin of trimethylamine in the mouse. Metabolism 41, 135-136 (1992).

20. Kanehisa, M. et al. From genomics to chemical genomics: new developments in KEGG. Nucleic acids research 34, D354-357, doi: 10.1093/nar/gkj102 (2006).

21. Mi, H. et al. The PANTHER database of protein families, subfamilies, functions and pathways. Nucleic acids research 33, D284-288, doi: 10.1093/nar/gki078 (2005)

22. Tatusov, R. L., Koonin, E. V. \& Lipman, D. J. A genomic perspective on protein families. Science 278, 631-637 (1997).

23. Serres, M. H. \& Riley, M. MultiFun, a multifunctional classification scheme for Escherichia coli K-12 gene products. Microbial ê comparative genomics $\mathbf{5}, 205-222(2000)$.

24. Burnell, A. M., Houthoofd, K., O'Hanlon, K. \& Vanfleteren, J. R. Alternate metabolism during the dauer stage of the nematode Caenorhabditis elegans. Exp Gerontol 40, 850-856, doi: 10.1016/j.exger.2005.09.006 (2005).

25. Jensen, V. L., Simonsen, K. T., Lee, Y.-H., Park, D. \& Riddle, D. L. RNAi Screen of DAF-16/FOXO Target Genes in C. elegans Links Pathogenesis and Dauer Formation. PloS one 5, e15902, doi: 10.1371/journal.pone.0015902 (2010).

26. Henderson, S. T. \& Johnson, T. E. daf-16 integrates developmental and environmental inputs to mediate aging in the nematode Caenorhabditis elegans. Current biology: CB 11, 1975-1980 (2001).

27. Murphy, C. T. et al. Genes that act downstream of DAF-16 to influence the lifespan of Caenorhabditis elegans. Nature 424, 277-283, doi: 10.1038/nature01789 (2003).

28. Lee, S. S., Kennedy, S., Tolonen, A. C. \& Ruvkun, G. DAF-16 target genes that control C. elegans life-span and metabolism. Science 300, 644-647, doi: 10.1126/science.1083614 (2003).

29. You, C. et al. Coordination of bacterial proteome with metabolism by cyclic AMP signalling. Nature 500, 301-306, doi: 10.1038/ nature12446 (2013).

30. Goldenbaum, P. E. \& Hall, G. A. Transport of cyclic adenosine $3^{\prime}, 5^{\prime}$-monophosphate across Escherichia coli vesicle membranes. Journal of bacteriology 140, 459-467 (1979).

31. Lee, S. J., Murphy, C. T. \& Kenyon, C. Glucose shortens the life span of C. elegans by downregulating DAF-16/FOXO activity and aquaporin gene expression. Cell metabolism 10, 379-391, doi: 10.1016/j.cmet.2009.10.003 (2009).

32. Chen, D. et al. Germline signaling mediates the synergistically prolonged longevity produced by double mutations in daf- 2 and rsks1 in C. elegans. Cell reports 5, 1600-1610, doi: 10.1016/j.celrep.2013.11.018 (2013).

33. Pierce, S. B. et al. Regulation of DAF-2 receptor signaling by human insulin and ins-1, a member of the unusually large and diverse C. elegans insulin gene family. Genes Dev 15, 672-686, doi: 10.1101/gad.867301 (2001).

34. Fielenbach, N. \& Antebi, A. C. elegans dauer formation and the molecular basis of plasticity. Genes \& development 22, 2149-2165, doi: 10.1101/gad.1701508 (2008).

35. Ottaviani, E. et al. Gut microbiota as a candidate for lifespan extension: an ecological/evolutionary perspective targeted on living organisms as metaorganisms. Biogerontology 12, 599-609, doi: 10.1007/s10522-011-9352-5 (2011).

36. Virk, B. et al. Excessive folate synthesis limits lifespan in the C. elegans: E. coli aging model. BMC biology 10, 67, doi: 10.1186/17417007-10-67 (2012)

37. Brooks, K. K., Liang, B. \& Watts, J. L. The influence of bacterial diet on fat storage in C. elegans. PloS one 4, e7545, doi: 10.1371/ journal.pone.0007545 (2009).

38. Xiao, R. et al. RNAi Interrogation of Dietary Modulation of Development, Metabolism, Behavior, and Aging in C. elegans. Cell reports 11, 1123-1133, doi: 10.1016/j.celrep.2015.04.024 (2015).

39. Samuel, B. S., Rowedder, H., Braendle, C., Felix, M. A. \& Ruvkun, G. Caenorhabditis elegans responses to bacteria from its natural habitats. Proceedings of the National Academy of Sciences of the United States of America 113, E3941-3949, doi: 10.1073/ pnas.1607183113 (2016).

40. Shtonda, B. B. \& Avery, L. Dietary choice behavior in Caenorhabditis elegans. The Journal of experimental biology 209, 89-102, doi: 10.1242/jeb.01955 (2006).

41. Lynn, D. A. et al. Omega-3 and -6 fatty acids allocate somatic and germline lipids to ensure fitness during nutrient and oxidative stress in Caenorhabditis elegans. Proceedings of the National Academy of Sciences of the United States of America 112, 15378-15383, doi: 10.1073/pnas.1514012112 (2015).

42. Pang, S. \& Curran, S. P. Adaptive capacity to bacterial diet modulates aging in C. elegans. Cell metabolism 19, 221-231, doi: 10.1016/j.cmet.2013.12.005 (2014).

43. Pang, S., Lynn, D. A., Lo, J. Y., Paek, J. \& Curran, S. P. SKN-1 and Nrf2 couples proline catabolism with lipid metabolism during nutrient deprivation. Nature communications 5, 5048, doi: 10.1038/ncomms6048 (2014).

44. Steinbaugh, M. J. et al. Lipid-mediated regulation of SKN-1/Nrf in response to germ cell absence. eLife 4, doi: 10.7554/eLife.07836 (2015).

45. Kang, C. \& Avery, L. Systemic regulation of starvation response in Caenorhabditis elegans. Genes \& development 23, 12-17, doi: 10.1101/gad.1723409 (2009).

46. Murphy, C. T. The search for DAF-16/FOXO transcriptional targets: approaches and discoveries. Exp Gerontol 41, 910-921, doi: 10.1016/j.exger.2006.06.040 (2006).

47. Honda, Y. \& Honda, S. The daf- 2 gene network for longevity regulates oxidative stress resistance and $\mathrm{Mn}$-superoxide dismutase gene expression in Caenorhabditis elegans. FASEB journal: official publication of the Federation of American Societies for Experimental Biology 13, 1385-1393 (1999).

48. Oh, S. W. et al. Identification of direct DAF-16 targets controlling longevity, metabolism and diapause by chromatin immunoprecipitation. Nature genetics 38, 251-257, doi: 10.1038/ng1723 (2006).

49. Gipson, G. T. et al. Multi-platform investigation of the metabolome in a leptin receptor defective murine model of type 2 diabetes. Mol Biosyst 4, 1015-1023, doi: 10.1039/b807332e (2008).

50. Birnby, D. A. et al. A transmembrane guanylyl cyclase (DAF-11) and Hsp90 (DAF-21) regulate a common set of chemosensory behaviors in caenorhabditis elegans. Genetics 155, 85-104 (2000).

51. Nicholson, J. K., Connelly, J., Lindon, J. C. \& Holmes, E. Metabonomics: a platform for studying drug toxicity and gene function. Nat Rev Drug Discov 1, 153-161, doi: 10.1038/nrd728 (2002)

52. Nicholson, J. K., Holmes, E., Lindon, J. C. \& Wilson, I. D. The challenges of modeling mammalian biocomplexity. Nat Biotechnol 22, 1268-1274, doi: 10.1038/nbt1015 (2004).

53. Nicholson, J. K. \& Wilson, I. D. Opinion: understanding 'global' systems biology: metabonomics and the continuum of metabolism. Nat Rev Drug Discov 2, 668-676, doi: 10.1038/nrd1157 (2003).

54. Backhed, F., Ley, R. E., Sonnenburg, J. L., Peterson, D. A. \& Gordon, J. I. Host-bacterial mutualism in the human intestine. Science 307, 1915-1920, doi: 10.1126/science.1104816 (2005).

55. Chen, Z. et al. Incorporation of therapeutically modified bacteria into gut microbiota inhibits obesity. The Journal of clinical investigation 124, 3391-3406, doi: 10.1172/JCI72517 (2014).

56. Coburn, C. M., Mori, I., Ohshima, Y. \& Bargmann, C. I. A cyclic nucleotide-gated channel inhibits sensory axon outgrowth in larval and adult Caenorhabditis elegans: a distinct pathway for maintenance of sensory axon structure. Development 125, 249-258 (1998). 
57. Rogers, A. N. et al. Life span extension via eIF4G inhibition is mediated by posttranscriptional remodeling of stress response gene expression in C. elegans. Cell Metab 14, 55-66, doi: 10.1016/j.cmet.2011.05.010 (2011).

58. Kim, H. W., Matin, A. \& Rhee, M. S. Microgravity Alters the Physiological Characteristics of Escherichia coli O157:H7 ATCC 35150, 43889, and 43895 Under Different Nutrient Conditions. Applied and environmental microbiology, doi: 10.1128/AEM.04037-13 (2014).

59. Hellemans, J., Mortier, G., De Paepe, A., Speleman, F. \& Vandesompele, J. qBase relative quantification framework and software for management and automated analysis of real-time quantitative PCR data. Genome biology 8, R19, doi: 10.1186/gb-2007-8-2-r19 (2007).

60. Chen, D., Thomas, E. L. \& Kapahi, P. HIF-1 modulates dietary restriction-mediated lifespan extension via IRE-1 in Caenorhabditis elegans. PLoS genetics 5, e1000486, doi: 10.1371/journal.pgen.1000486 (2009).

61. Raizen, D., Song, B. M., Trojanowski, N. \& You, Y. J. Methods for measuring pharyngeal behaviors. WormBook: the online review of C. elegans biology 1-13, doi: 10.1895/wormbook.1.154.1 (2012).

62. Sawin, E. R., Ranganathan, R. \& Horvitz, H. R. C. elegans locomotory rate is modulated by the environment through a dopaminergic pathway and by experience through a serotonergic pathway. Neuron 26, 619-631 (2000).

63. Glater, E. E., Rockman, M. V. \& Bargmann, C. I. Multigenic natural variation underlies Caenorhabditis elegans olfactory preference for the bacterial pathogen Serratia marcescens. G3 4, 265-276, doi: 10.1534/g3.113.008649 (2014).

64. Gomez-Amaro, R. L. et al. Measuring Food Intake and Nutrient Absorption in Caenorhabditis elegans. Genetics 200, 443-454, doi: 10.1534/genetics.115.175851 (2015).

65. Bendesky, A., Tsunozaki, M., Rockman, M. V., Kruglyak, L. \& Bargmann, C. I. Catecholamine receptor polymorphisms affect decision-making in C. elegans. Nature 472, 313-318, doi: 10.1038/nature09821 (2011).

66. Portman, D. S. \& Emmons, S. W. Identification of C. elegans sensory ray genes using whole-genome expression profiling. Developmental biology 270, 499-512, doi: 10.1016/j.ydbio.2004.02.020 (2004).

\section{Acknowledgements}

We would like to thank Gordon Lithgow, Jennifer Garrison, Mark Watson, Mark Lucanic and Matthew McGee for their comments and contribution to the manuscript. We would like to thank members of the Kapahi and Lithgow labs for discussions and suggestions. We would like to thank Cori Bargmann for tyra-3 rescue strains. This work was funded by grants from American Federation for Aging Research and the NIH (R01AG038688 and RL1 AAG032113).

\section{Author Contributions}

M.V., J.K., A.K., T.M. and P.K. designed the study. M.V., T.M., D.K. and J.K. established the dauer and lifespan assays conditions. N.N., A.K., L.B., J.K. and M.V. performed the dauer and lifespan assays. S.K. helped with cAMP estimation. A.K., M.V., A.S. and P.L. performed DAF-16 localization experiments. A.K., J.K., R.B., D.K., M.G., S.D.M. and C.N. analyzed expression data. A.K., M.V. and P.K. wrote the manuscript.

\section{Additional Information}

Supplementary information accompanies this paper at http://www.nature.com/srep

Competing financial interests: The authors declare no competing financial interests.

How to cite this article: Khanna, A. et al. A genome-wide screen of bacterial mutants that enhance dauer formation in C. elegans. Sci. Rep. 6, 38764; doi: 10.1038/srep38764 (2016).

Publisher's note: Springer Nature remains neutral with regard to jurisdictional claims in published maps and institutional affiliations.

(c) (i) This work is licensed under a Creative Commons Attribution 4.0 International License. The images or other third party material in this article are included in the article's Creative Commons license, unless indicated otherwise in the credit line; if the material is not included under the Creative Commons license, users will need to obtain permission from the license holder to reproduce the material. To view a copy of this license, visit http://creativecommons.org/licenses/by/4.0/

(C) The Author(s) 2016 